\title{
Whole blood and blood components from vertebrates differentially affect egg formation in three species of anautogenous mosquitoes
}

\author{
Ruby E. Harrison, Mark R. Brown and Michael R. Strand*
}

\begin{abstract}
Background: Most female mosquitoes are anautogenous and must blood feed on a vertebrate host to produce eggs. Prior studies show that the number of eggs females lay per clutch correlates with the volume of blood ingested and that protein is the most important macronutrient for egg formation. In contrast, how whole blood, blood fractions and specific blood proteins from different vertebrates affect egg formation is less clear. Since egg formation is best understood in Aedes aegypti, we examined how blood and blood components from different vertebrates affect this species and two others: the malaria vector Anopheles gambiae and arbovirus vector Culex quinquefasciatus.
\end{abstract}

Methods: Adult female mosquitoes were fed blood, blood fractions and purified major blood proteins from different vertebrate hosts. Markers of reproductive response including ovary ecdysteroidogenesis, yolk deposition into oocytes and number of mature eggs produced were measured.

Results: Ae. aegypti, An. gambiae and C. quinquefasciatus responded differently to meals of whole blood, plasma or blood cells from human, rat, chicken and turkey hosts. We observed more similarities between the anthropophiles Ae. aegypti and An. gambiae than the ornithophile C. quinquefasciatus. Focusing on Ae. aegypti, the major plasma-derived proteins (serum albumin, fibrinogen and globulins) differentially stimulated egg formation as a function of vertebrate host source. The major blood cell protein, hemoglobin, stimulated yolk deposition when from pigs but not humans, cows or sheep. Serum albumins from different vertebrates also variably affected egg formation. Bovine serum albumin (BSA) stimulated ovary ecdysteroidogenesis, but more weakly induced digestive enzyme activities than whole blood. In contrast, BSAderived peptides and free amino acids had no stimulatory effects on ecdysteroidogenesis or yolk deposition into oocytes. Conclusions: Whole blood, blood fractions and specific blood proteins supported egg formation in three species of anautogenous mosquitoes but specific responses varied with the vertebrate source of the blood components tested.

Keywords: Mosquito, Oogenesis, Reproduction, Endocrinology, Diet

\section{Background}

Mosquitoes vector a number of bloodborne pathogens, including the causative agents of malaria, dengue fever and yellow fever, that annually result in $>200$ million

*Correspondence: mrstrand@uga.edu

Department of Entomology, The University of Georgia, 120 Cedar Street,

420 Biological Sciences, Athens, GA 30602, USA human infections and 725,000 deaths worldwide [1]. Adult mosquitoes of both sexes can subsist entirely on nutritional resources such as nectar or fruit juices that primarily contain carbohydrates [2]. Plant sugars provide energy for maintenance, allow for metabolic reserve replenishment, extend life span and are used directly to fuel flight [3]. However, most species are also anautogenous, which means that females cannot produce eggs

c) The Author(s) 2021. This article is licensed under a Creative Commons Attribution 4.0 International License, which permits use, sharing, adaptation, distribution and reproduction in any medium or format, as long as you give appropriate credit to the original author(s) and the source, provide a link to the Creative Commons licence, and indicate if changes were made. The images or other third party material in this article are included in the article's Creative Commons licence, unless indicated otherwise in a credit line to the material. If material is not included in the article's Creative Commons licence and your intended use is not permitted by statutory regulation or exceeds the permitted use, you will need to obtain permission directly from the copyright holder. To view a copy of this licence, visit http://creativeco mmons.org/licenses/by/4.0/. The Creative Commons Public Domain Dedication waiver (http://creativecommons.org/publicdomain/ zero/1.0/) applies to the data made available in this article, unless otherwise stated in a credit line to the data. 
without consuming blood from a vertebrate host [4]. The ability to blood feed and produce eggs in consecutive cycles over a lifespan of 4-8 weeks further underlies how anautogenous mosquitoes acquire and transmit pathogens among vertebrate hosts [4].

Mature eggs develop in the ovaries from primary egg chambers comprised of an oocyte, nurse cells and enveloping follicle cells [5]. Primary egg chambers remain developmentally arrested until consumption of a bloodmeal, which activates the vitellogenic phase of oogenesis [6]. The processes regulating the vitellogenic phase are currently best understood in Aedes aegypti where consumption of a bloodmeal stimulates the release of two types of peptide hormones, ovary ecdysteroidogenic hormone (OEH) and insulin-like peptides (ILPs), from the brain [6]. OEH and ILP family members such as ILP3 bind distinct but related receptor tyrosine kinases named the insulin (IR) and OEH (OEHR) receptors [79]. Ligand binding activates the IR and OEHR on ovary membranes, which activates the division of follicle cells and endoreplication of nurse cells [5]. OEH strongly stimulates follicle cells to produce ecdysteroid hormones, chiefly ecdysone (ECD) [8-11], while ILP3 is required for expression of trypsin-like enzymes in the midgut that digest the bloodmeal [12-15]. ECD released from follicle cells is converted to 20-hydroxyecdysone (20E) in fat body adipocytes, which together with nutrient signaling via the target of rapamycin (TOR) pathway stimulates the synthesis of vitellogenin $(\mathrm{Vg})$ and other yolk components [16]. Mature eggs are formed upon completion of yolk uptake and deposition of a chorion (egg shell) by follicle cells $[17,18]$. Females then lay up to 120 eggs in a single clutch by $72 \mathrm{~h}$ post-bloodmeal [4].

Whole vertebrate blood is a colloidal suspension of predominantly red blood cells (erythrocytes) in plasma. Whole blood also consists primarily of protein by dry weight, with only small amounts of lipid, carbohydrate and trace elements [19]. However, hematological parameters also vary among vertebrates with significant differences observed among species in red blood cell diameter, hematocrit (packed cell volume), hemoglobin level, plasma protein content and salt, mineral and micronutrient concentrations [20-22]. Intraspecific variation is also observed among individual hosts because factors such as age, sex and health influence hematological properties [23]. These sources of variation in blood composition have potentially important consequences for mosquitoes since the nutritional quality of blood has been previously implicated in reproductive fitness [24-26].

Several studies indicate that anautogenous mosquitoes produce eggs after consuming blood from different vertebrates [26-42] with clutch size correlating with blood volume ingested [32, 43-47] and protein being the most important macronutrient [48-52]. Reviews of the early literature suggest anautogenous mosquitoes produce more eggs after blood feeding on amphibians, reptiles or birds than on mammals $[36,53]$. Amino acid balance and the nucleated erythrocytes of amphibians, reptiles and birds have both been suggested to be more suitable for egg formation than the amino acid composition and anucleate erythrocytes of mammalian blood [31, 36, 54, 55]. The packed cell volume of blood has been shown to influence reproductive fitness, survival and vectorial capacity in mosquito species that undergo prediuresis, i.e. that concentrate red blood cells in the midgut and excrete plasma continuously while blood-feeding [56-60]. Some studies indicate the cellular fraction of blood from different host species contributes to or is indispensable for egg formation in several anautogenous species including Ae. aegypti [36, 49, 55, 58, 61-64]. In contrast, a recent study of bovine blood fractions concluded that only plasma supported egg formation by Ae. aegypti [65], and lyophilized plasma forms a suitable artificial diet for Aedes and Anopheles mosquitoes [66]. The most abundant protein in bovine plasma, serum albumin, has also been shown to stimulate high levels of egg formation in Ae. aegypti and select other species [65, 67-74].

In assessing the preceding literature, we noted that most studies focus on single mosquito species and often use differing assay approaches, which could contribute to varying conclusions about how blood and blood components from different vertebrates affect egg formation. We also noted that most studies do not examine how blood components affect key physiological processes that regulate vitellogenesis. Since egg formation is best understood in Ae. aegypti, we revisited how blood and blood components from different vertebrates affect this species and two others: the malaria vector Anopheles gambiae and arbovirus vector Culex quinquefasciatus. In the first part of our study, we assessed feeding rates, yolk deposition, the number of eggs laid and hatch rates in these three mosquito species when fed whole blood or blood fractions from different vertebrates. We then focused the second part of our study on Ae. aegypti, where we investigated how blood-derived and other proteins affect yolk deposition, digestive enzyme expression, and ovary ecdysteroidogenesis. Our results indicate that plasma, blood cells and particular proteins stimulate mosquito egg formation, but outcomes differ with the vertebrate source of the components tested.

\section{Methods}

\section{Mosquito rearing}

The University of Georgia (UGAL) strain of Aedes aegypti was established from wild-caught females in Athens, GA, 
in the early 1970s. Morphological characters identify this strain as the subspecies Aedes aegypti aegypti [75], but for brevity we henceforth refer to the UGAL strain as $A e$. aegypti. The G3 strain of Anopheles gambiae was originally obtained from the Centers for Disease Control and Prevention (CDC) in Atlanta and has been maintained in our insectary since 2004. The CDC MR4/BEI strain of Culex quinquefasciatus has been maintained in our insectary since 2011. All mosquitoes were reared under a $12 \mathrm{~h}$ light: $12 \mathrm{~h}$ dark photoperiod at $26^{\circ} \mathrm{C}$ and $70 \%$ relative humidity. Larvae of each species were reared in pans at a density of $\sim 150$ larvae per liter of deionized water and fed daily until pupation at 6 days post-hatch. Ae. aegypti and $C$. quinquefasciatus were maintained on a larval diet consisting of ground rat chow pellets (LabDiet 5001), lactalbumin (Sigma) and torula yeast extract (Bio-Serve) mixed in a ratio of 1:1:1 by volume, referred to as rat chow mix. An. gambiae larvae were maintained on a diet of pulverized TetraMin tropical flakes (Tetra). Adult mosquitoes were provided water and $10 \%$ sucrose in water $a d$ libitum. For colony maintenance, adults from each generation were blood-fed 3-5 days post-eclosion to obtain eggs. Ae. aegypti and C. quinquefasciatus were blood-fed from an anesthetized male laboratory rat (Sprague Dawley), while An. gambiae was fed defibrinated rabbit blood (Hemostat Laboratories) using a membrane feeder.

\section{Membrane feeding}

Membrane feeder assays were conducted using a simple method that has not previously been reported in the literature. In brief, meals were pipetted into the cut-off caps of $1.7-\mathrm{ml}$ microfuge tubes (Olympus Plastics 22-282), which hold a 200- $\mu$ l volume. Parafilm ${ }^{\circledR} \mathrm{M}$
(Millipore Sigma P7543) was stretched over these caps to produce small capacity membrane feeders. Four to eight caps, depending on the number of mosquitoes fed (ranging 15-50), were then placed on the mesh tops of small mosquito cages $(10 \times 8.5 \mathrm{~cm})$, membrane side down, and topped with a USB-chargeable hand warmer from either Thermotrek $\odot$ or FourHeart ${ }^{\circledR}$ (Fig. 1). When operated at the lowest heating level, these electric handwarmers maintain stable temperatures of 40 and $42{ }^{\circ} \mathrm{C}$, respectively.

All whole blood, blood fraction and protein meals contained ATP at a final concentration of $1 \mathrm{mM}$, which is a potent phagostimulant at this concentration [71, 76]. Whole bloods used in membrane feeder assays were purchased from Hemostat Laboratories (Dixon, CA) and contained the anticoagulant sodium citrate unless otherwise specified. Due to the rapid expiration of bottled blood, whole blood and blood fractions were always offered to mosquitoes within 4 days of blood shipment arrival. Whole bloods were centrifuged at $2000 \times g$ for 5 min to produce plasma and cell fractions that primarily consisted of erythrocytes. Undiluted plasma was put into membrane feeders while cell fractions were triple-washed in phosphate-buffered saline (PBS) [65] and then resuspended at a hematocrit of 50\% in fresh PBS, which approximated the mean packed cell volume determined for many mammalian and avian species [21]. All proteins, peptides and amino acids used in assays were commercially purchased (Sigma Aldrich, St. Louis, MO; Difco, Detroit, MI) and fed at a concentration of $200 \mathrm{mg} / \mathrm{ml}$ in PBS plus ATP. An L-amino acid solution containing the 20 amino acids present in most eukaryotic proteins was prepared in

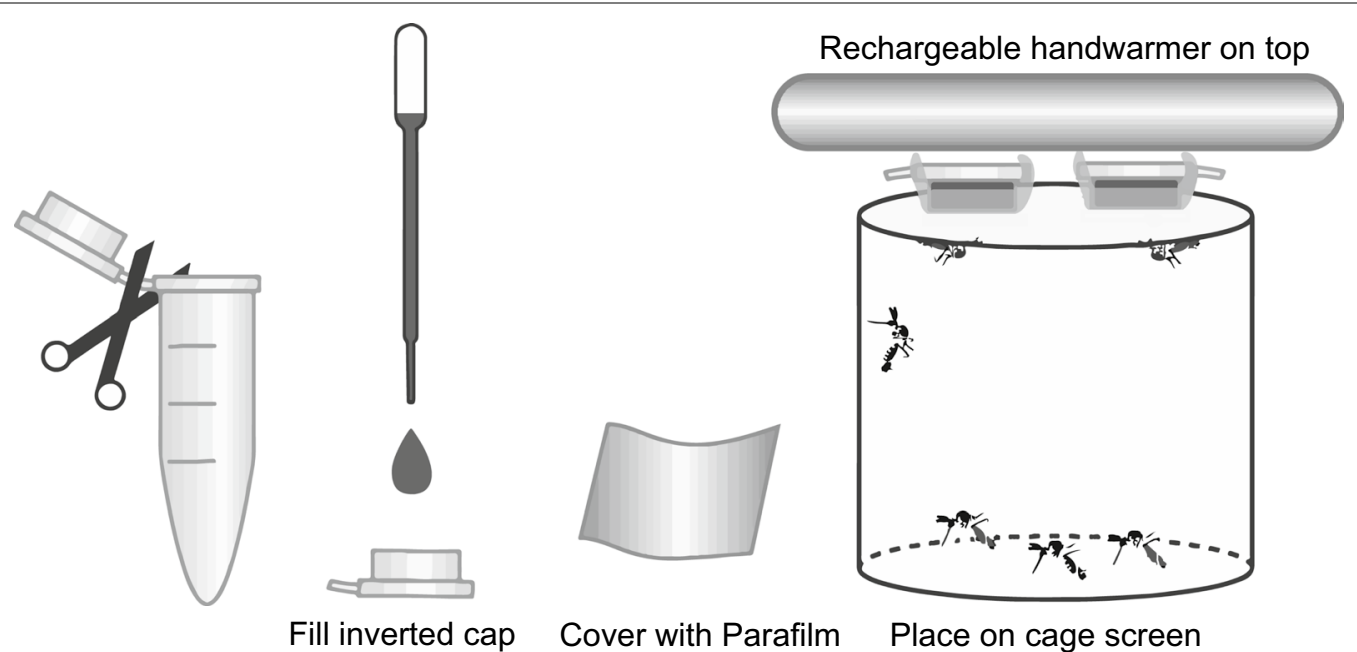

Fill inverted cap Cover with Parafilm Place on cage screen

Fig. 1 Schematic illustrating the membrane feeder system used during the study. See "Methods" for details 
PBS at molarities that matched the amino acid content of BSA at $200 \mathrm{mg} / \mathrm{ml}$ with the exception of tyrosine, which was reduced to $50 \%$ of BSA to fully solubilize (Additional file 1: Table S1).

\section{Bioassays}

To estimate the amount of blood mosquitoes consumed, 4-day post-emergence females were chilled and weighed in cohorts of ten using an analytical balance (Ohaus DV215CD). The average weight per individual NBF female was calculated from this value. Each cohort of ten was returned to a cage with access to water for $8 \mathrm{~h}$ and then presented membrane feeders containing different solutions for $30 \mathrm{~min}$. Immediately following blood-feeding, females were then chilled and the replete individuals tallied and weighed, which yielded an average bloodmeal weight per individual $(\mathrm{mg})$. Bloodmeal weights were always taken within 15 min of blood-feeding since $A e$. aegypti females undergo diuresis and excretion of excess blood-derived water during the first hour post-bloodmeal [4]. Each treatment was replicated ten times.

To assess clutch size, replete females were isolated within $1 \mathrm{~h}$ post-meal and individually placed in small cages $\left(34 \times 30 \mathrm{~mm}^{2}\right)$ containing a paper towel-lined glass bowl half-filled with deionized water for oviposition. Glass bowls were checked for eggs daily and retrieved once oviposition had occurred or after 7 days post-meal. Clutch size was recorded as the number of eggs laid, while viability was calculated as the number of viable larvae produced per female. Ae. aegypti females laid eggs on the paper towel lining, which was dried and kept in a humid container for 10 days prior to hatching. C. quinquefasciatus and An. gambiae oviposit directly on the surface of the water; eggs from these species hatched within $72 \mathrm{~h}$ of oviposition at which time larvae were counted.

Oocyte maturation as measured by yolk deposition was measured using previously established methods [7, 77]. Briefly, ovaries were dissected from replete females $48 \mathrm{~h}$ after feeding, and the length of visible yolk per oocyte along the anterior-posterior access was measured using an ocular micrometer mounted on a stereomicroscope. For each female, measurements were taken for three oocytes per ovary pair, and averaged. Yolk deposition per female at $48 \mathrm{~h}$ post-meal was measured and averaged for 20-50 individual females per treatment.

\section{Ecdysteroid assays}

Total ecdysteroids secreted by ovaries were quantified using an enzyme-linked immunosorbent assay (EIA) [10]. Ovaries were dissected from females $20 \mathrm{~h}$ after feeding, which corresponds with when ecdysteroid production peaks in ovaries after consumption of rat blood [8]. The ovaries from two females were pooled and incubated together in $60 \mu \mathrm{l}$ Beyenbach's saline [10] on a shaker for $6 \mathrm{~h}$ at $27{ }^{\circ} \mathrm{C}$ and $\sim 90 \% \mathrm{RH}$. Following this incubation period, medium supernatant containing secreted ecdysteroids was collected and frozen at $-20{ }^{\circ} \mathrm{C}$. Ecdysteroid titer was then determined by EIA using the EAB27 primary antibody and 20-hydroxyecdysone (Sigma) as a standard [78].

\section{Midgut trypsin-like serine protease activity and relative quantitative polymerase chain reaction (rqRT-PCR) assays} Trypsin-like serine protease activity was measured in midguts dissected from females $24 \mathrm{~h}$ after feeding using an established $N_{\alpha}$-benzoyl-L-arginine 4-nitroanilide hydrochloride (BApNA) assay [15]. In brief, each midgut was placed in Tris $\mathrm{HCl} 0.02 \mathrm{M}$ buffer containing $\mathrm{CaCl}_{2}$ $0.02 \mathrm{M}(200 \mu \mathrm{l})$, sonicated briefly, and then centrifuged at $12,000 \times g$ for $5 \mathrm{~min}$. Ten $\mu \mathrm{l}$ of supernatant $(0.05 \mathrm{mid}-$ gut equivalent) was then added to $90 \mu \mathrm{l}$ Tris- $\mathrm{CaCl}_{2}$ buffer and $200 \mu \mathrm{l}$ of BApNA (4 mM) (Sigma). After incubating on a rocker for $15 \mathrm{~min}$ at room temperature, absorbance was read at $405 \mathrm{~nm}$ (BioTek plate reader) and quantified based on trypsin standards (bovine pancreas, Sigma).

For rqRT-PCR assays, midguts were collected $24 \mathrm{~h}$ after females fed to repletion on membrane feeders and extracted using Trizol reagent (Ambion). Samples consisted of pooled midguts of two females, with four biological replicates per treatment. cDNA templates were generated using the iScript cDNA synthesis kit (BioRad) while gene-specific primers were designed and purchased (IDT) for the following targets: Aedes aegypti 5G1 (Aa5G1, X64363.1; forward 5'-CTGTGGAGGATC GCTACTTTC-3'; reverse 5'- GATGGCGGTTGACCT TCTTA-3'; Aedes aegypti late trypsin (AaLT, M77814.1; forward 5'-GGAAGTGATACCTTTACCGACCG-3'; reverse 5'-GATCACCAACGGGCTGTAGGC-3'), Aedes aegypti serine protease VI (AaSPVI, GQ398048; forward 5'AGGAATGCCACAAGGCTTACTTGA-3'; reverse 5'-CCATAACCCCAGGATACCACT-3'); and Aedes aegypti serine protease VII (AaSPVII, GQ398049; forward 5'-CGAATGGTATGTGCCGGTTA-3'; reverse 5'-CAA CTCCGACCAGGGTATTG-3') [79]. Aedes aegypti actin (AaACT, KY000701) was used as reference gene using primers forward 5'-CGTTCGTGACATCAAGGA AA-3' and reverse 5'-GAACGATGGCTGGAAGAG AG-3' [79]. Reactions contained $3 \mu \mathrm{l} \mathrm{cDNA,} 2 \mu \mathrm{l}$ forward/ reverse primers $5 \mu \mathrm{M}$ and $5 \mu$ iQ SYBR Green Supermix (Bio-Rad 170-8882) and were run using a Rotor-Gene Q real-time PCR cycler (Qiagen) under the following conditions: denaturation at $95{ }^{\circ} \mathrm{C}$ for $10 \mathrm{~s}$ and annealing at $60{ }^{\circ} \mathrm{C}$ for $45 \mathrm{~s}$, for a total of 30 cycles. Relative transcript 
abundance of each target gene relative to $A a A C T$ and fold change compared to non-fed controls was calculated using the $\Delta \Delta C$ T method [80].

\section{Data analysis}

Individual adult females were the unit of replication in assays that assessed proportions of replete or ovipositing females, yolk deposition, time (days) taken to oviposit following ingestion of a meal and egg clutch size. Isolated midguts from individuals served as the unit of replication for trypsin activity assays. For feeding assays, the number of engorged females was summed across replicates and divided by the total offered the meal to generate an overall proportion of replete females.

All proportional data sets (e.g. proportion of females to blood-feed, proportion of females to oviposit, proportion of eggs to hatch) were assessed for significant differences among treatments using a contingency table analysis (chi-squared test). Continuous data such as yolk deposition, number of days taken to oviposit, egg clutch size and trypsin activity per midgut were analyzed for differences among treatment means using analysis of variance (ANOVA). The continuous-type data sets were initially assessed for normality using the Shapiro-Wilk $\mathrm{W}$ test on residuals and Bartlett's test for homogeneity of variances. If both Shapiro-Wilk and Bartlett's tests yielded non-significant $p$-values, treatment means were then compared using the parametric one-way ANOVA, followed by Tukey's Honestly Significant Difference multiple comparisons post-hoc analysis. If the continuous data were found to be non-normal, a Kruskal-Wallis non-parametric alternative was used instead, followed by Dunn's post-hoc multiple comparison test. Data on the weight of blood ingested, ecdysteroid production by ovaries and serine protease transcript profiles were generated from replicated samples of pooled females as previously described under Bioassays. Treatment means from these data sets were also analyzed by oneway ANOVA following the assessment of normality described for the other continuous data sets. All data analysis was performed using R, version 3.3.2. GUI 1.68 Mavericks build (7288). Tables were generated using Microsoft Excel v16.39 and figures generated using GraphPad Prism v8.4.2.

\section{Results}

\section{UGAL strain Aedes aegypti similarly respond to blood} feeding on a rat or membrane feeders containing rat blood We first assessed whether females exhibited any differences in feeding, survival, oviposition or number of eggs laid when given an anesthetized rat versus membrane feeders filled with commercially purchased bottled blood. Because anticoagulants in blood have previously been shown to affect mosquito feeding success and survival [81], we compared mosquito responses to defibrinated rat blood or rat blood containing three different anticoagulants: Na citrate, Na heparin or EDTA. Proportionately fewer females fed to repletion after $30 \mathrm{~min}$ on a rat but average meal size (mg) was similar across treatments except for blood containing EDTA (Table 1). Survival over the course of these assays was unaffected by treatment since no replete females died. Days to oviposition were also similar among treatments except for females that consumed blood with EDTA, which oviposited approximately 1 day sooner than females that consumed blood from a rat (Table 1). No differences were detected in number of eggs laid (clutch sizes) among treatments

Table 1 Feeding, oviposition time and eggs produced per Ae. aegypti female provided a live rat or bottled bloods in membrane feeders

\begin{tabular}{|c|c|c|c|c|c|}
\hline & \multirow[t]{2}{*}{ Live rat } & \multicolumn{4}{|c|}{ Bottled rat blood with anticoagulant } \\
\hline & & Defibrinated & Na citrate & Na heparin & EDTA \\
\hline Proportion of replete females ${ }^{1}$ & $46 / 100$ & $67 / 100$ & $66 / 100$ & $61 / 100$ & $59 / 100$ \\
\hline Ingested blood (mg) per female & $2.90 \pm 0.94^{\mathrm{a}}$ & $2.45 \pm 0.32^{\mathrm{a}}$ & $2.27 \pm 0.33^{\mathrm{a}}$ & $2.15 \pm 0.64^{\mathrm{a}}$ & $1.26 \pm 0.55^{b}$ \\
\hline $\begin{array}{l}\text { Females examined for time to oviposi- } \\
\text { tion and eggs laid }{ }^{2}\end{array}$ & 20 & 8 & 20 & 18 & 10 \\
\hline Time to oviposition (days) ${ }^{3}$ & $3.90 \pm 0.85^{\mathrm{a}}$ & $3.50 \pm 1.41^{a, b}$ & $3.60 \pm 0.50^{a, b}$ & $3.28 \pm 0.9^{a, b}$ & $3.00 \pm 0.00^{b}$ \\
\hline Total eggs per female & $123.2 \pm 48.0$ & $140.6 \pm 37.7$ & $110.0 \pm 44.7$ & $115.3 \pm 48.4$ & $137.4 \pm 25.1$ \\
\hline Eggs per mg blood consumed ${ }^{3}$ & $46.7 \pm 21.0^{\mathrm{a}}$ & $57.9 \pm 15.5^{a, b}$ & $49.2 \pm 20.0^{\mathrm{a}}$ & $57.6 \pm 26.1^{a, b}$ & $69.0 \pm 12.6^{b}$ \\
\hline
\end{tabular}

\footnotetext{
${ }^{1}$ Females were fed in cohorts of 10 per cage for a total of 100 females per treatment. $x^{2}=11.76, \mathrm{df}=4, p=0.02$

${ }^{2}$ A subsample of replete females was examined to determine time to oviposition, total eggs per female (clutch size) and eggs per mg of blood consumed

${ }^{3}$ For each indicated row, the mean \pm SD for each treatment is indicated. Different small case letters after a given mean indicates treatments significantly differed from one another after ANOVA or Kruskal-Wallis and post hoc Tukey Kramer or Dunn's tests, respectively

Different letters to the right of means in each row indicated the treatments significantly differed from one another $(p \leq 0.05)$.
} 
although normalizing the data by bloodmeal size suggested females laid more eggs per mg of blood containing EDTA (Table 1). Overall, few differences were detected between females that fed on a rat and membrane feeders containing commercially purchased rat bloods. We thus used membrane feeders rather than living hosts to compare the effects of different bloods and blood components from different vertebrates on egg formation, using sodium citrate as the anticoagulant for all treatments.

\section{Whole blood, plasma and blood cells from four vertebrates differentially support egg formation}

Multiple olfactory and visual cues have been implicated in attracting anautogenous female mosquitoes to vertebrates [82]. While most anautogenous mosquitoes are generalists that bite multiple vertebrates, Ae. aegypti shows evidence of evolving from a generalist feeder in its native Africa into two subspecies: Ae. aegypti formosus, which remains a generalist in Africa, and Ae. aegypti aegypti, such as the UGAL strain used in this study, which has been introduced worldwide and preferentially feeds on humans $[25,75]$. Vertebrate blood is also known to differ among species with the protein content of plasma usually being higher in mammals than other taxa, while red blood cells vary from being anucleate in mammals to large and nucleate in birds, reptiles and amphibians [19]. However, it is largely unclear whether anautogenous species with host preferences derive reproductive benefits from the blood of preferred hosts. We therefore first asked whether females of each species differentially fed or laid eggs after feeding on commercially purchased bloods from two mammals (human, rat) and two birds (chicken, turkey) in no-choice membrane feeder assays that lacked most olfactory and visual cues associated with living hosts.

We detected no differences among treatments in the proportion of UGAL Ae. aegypti females that fed to repletion or the number of eggs females laid (Fig. 2a, b). In contrast, large differences were detected in egg hatch rates with turkey blood producing the largest yields and chicken blood producing the smallest (Additional file 1: Table S2). We next separated each whole blood into its plasma and cell fraction. No differences were detected in the proportion of females that fed to repletion on each plasma (Fig. 2c), whereas large differences were detected in the number of eggs laid because of females producing none after feeding on bird plasmas (Fig. 2d). Egg hatch rates were also lower for females that consumed human versus rat plasma (Additional file 1: Table S2). Dissection of females that consumed avian plasmas showed that oocytes contained little yolk (ca. 40-100 $\mu \mathrm{m}$ ), indicating that avian plasmas initiated vitellogenesis but did not sustain full maturation of oocytes. More females fed to repletion on rat than other blood cells (Fig. 2e), while females that consumed human blood cells laid no or very few eggs that also exhibited low hatch rates (Fig. 2f; Additional file 1: Table S2).

To assess whether the preceding outcomes were generalizable, the same treatments were tested with $A n$. gambiae, which is strongly anthropophilic, and $C$. quinquefasciatus, which in the field preferentially feeds on birds but also feeds on several mammals including humans [83, 84]. The proportion of An. gambiae and C. quinquefasciatus that fed to repletion on whole blood, plasma or cell fractions varied among treatments but overall showed no tendencies in terms of An. gambiae more readily feeding on human and $C$. quinquefasciatus more readily feeding on avian-derived components (Figs. 3 and 4). An. gambiae laid the fewest eggs after consuming whole chicken blood; C. quinquefasciatus laid the most eggs on avian whole bloods, but hatch rates showed no tendencies in either species (Figs. 3 and 4, Additional file 1: Table S2). Broadly similar patterns to Ae. aegypti were observed when blood fractions were fed to An. gambiae with females laying no eggs after consuming avian plasmas, very small numbers of eggs after consuming human blood cells and relatively large numbers of eggs after feeding on avian blood cells (Fig. 3). Egg hatch rates for An. gambiae were also overall lowest after consuming human plasma (Additional file 1: Table S2). C. quinquefasciatus laid relatively small numbers of eggs after consuming all plasmas and laid almost no eggs after consuming human blood cells, but laid large numbers of eggs after consuming avian blood cells that were also similar overall to the number of eggs laid after consuming whole avian bloods (Fig. 4). Egg hatch

(See figure on next page.)

Fig. 2 Feeding and egg laying by Ae. aegypti in response to blood and blood fractions from four vertebrates. Females were provided whole blood $(\mathbf{a}, \mathbf{b})$, plasma $(\mathbf{c}, \mathbf{d})$ or blood cells $(\mathbf{e}, \mathbf{f})$ containing ATP $1 \mathrm{mM}$ in membrane feeders from human, rat, chicken or turkey. $\mathbf{a}, \mathbf{c}$ and $\mathbf{e}$ Comparison of the proportion of females that fed to repletion. Numbers below the $x$-axis indicate the total number of individual females tested for a given treatment. Statistical significance after contingency table analysis is indicated by asterisks: ${ }^{*} p<0.05 ;{ }^{* *} p<0.001 ;{ }^{* *} p<0.0001 ; n s$ not significant. $\mathbf{b}$, $\mathbf{d}$, and $\mathbf{f}$ Comparison of the number of eggs each female that fed to repletion laid. Numbers below the $x$-axis indicate the total number of individual replete females assessed for egg lay for each treatment. Horizontal bars indicate the mean \pm SD. Within each graph different small case letters indicate treatments significantly differed from one another after a Kruskal-Wallis and post-hoc Dunn's test ( $p \leq 0.05)$ 


\section{Aedes aegypti}
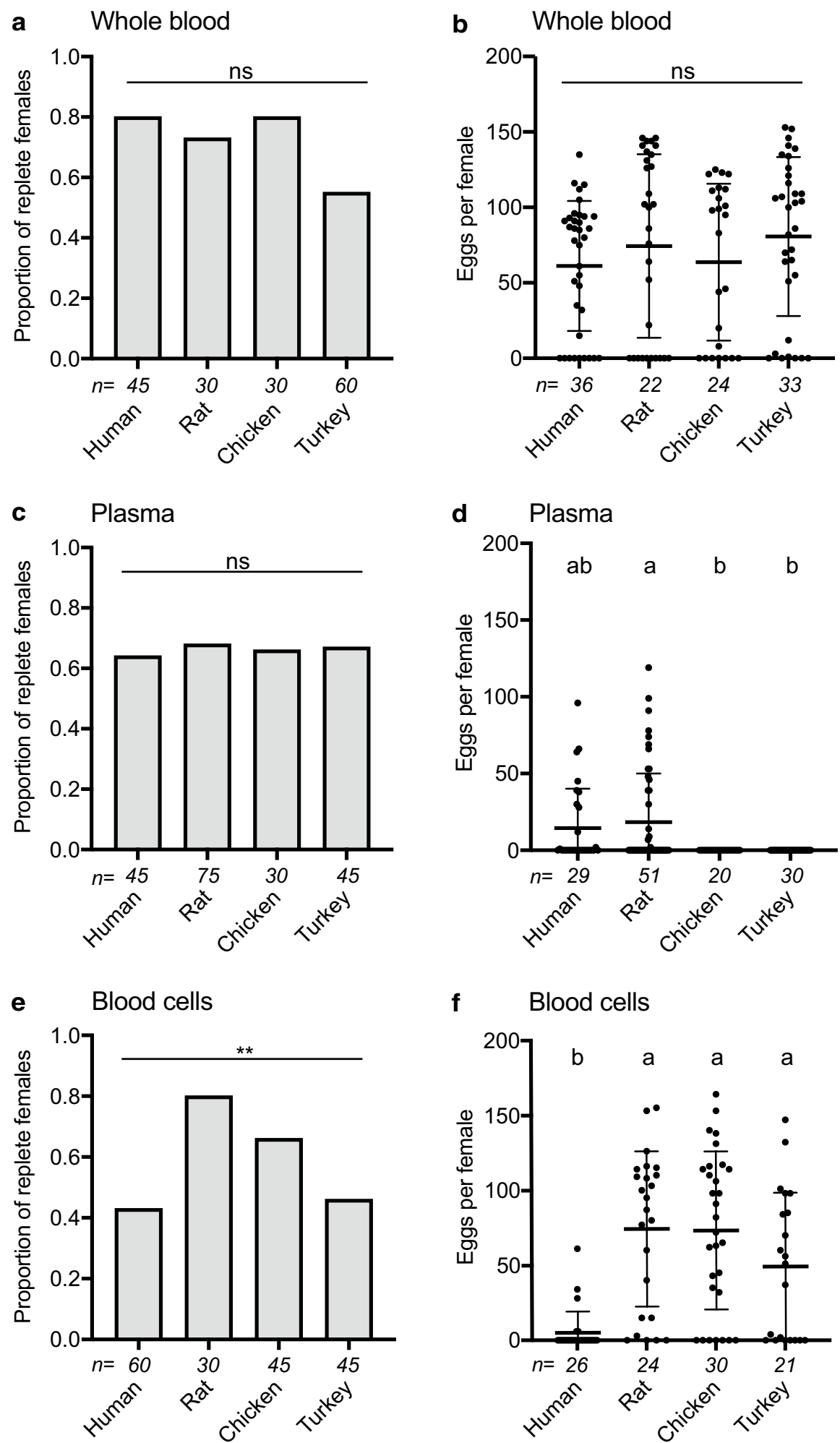
rates for C. quinquefasciatus also overall trended lower after feeding on plasmas than blood cells (Additional file 1: Table S2).

\section{Serum albumins and hemoglobin from different vertebrates variably stimulate egg formation in Ae. aegypti} We next assessed how specific blood-associated proteins affected egg formation and key physiological processes that regulate vitellogenesis. We focused these studies on $A e$. aegypti because: (i) regulation of egg formation in mosquitoes is best understood in this species and (ii) preliminary studies identified issues in feeding purified proteins to $A n$. gambiae and $C$. quinquefasciatus, which prevented comparison of outcomes to Ae. aegypti. The plasma fraction of vertebrate blood primarily contains three types of proteins (albumin, fibrinogen and globulins) while the cellular fraction by dry weight consists primarily of hemoglobin [85]. We fed Ae. aegypti females each of these proteins from at least two vertebrates at $200 \mathrm{mg} / \mathrm{ml}$ in PBS plus ATP, which approximates the total protein content of whole human blood. Females that fed to repletion were then dissected $48 \mathrm{~h}$ later to determine whether the vitellogenic phase of oogenesis had been activated by measuring yolk deposition, which increases linearly in oocytes when females consume whole blood [18]. Serum albumins from several vertebrates stimulated yolk deposition but only bovine serum albumin (BSA) from cow generated outcomes that were equivalent to females fed whole rat blood (Fig. 5a). Little or no yolk deposition occurred when females consumed fibrinogens or bovine gamma-globulins, while modest yolk deposition occurred after consumption of human gamma-globulins (Fig. 5a).

Vertebrate hemoglobins consist of two alpha and two beta subunits that form heterotetramers with an approximate aggregate mass of $65 \mathrm{kDa}$ [86]. Pig hemoglobin stimulated a variable but often similar yolk deposition response as BSA and whole rat blood, whereas human and cow hemoglobin did not (Fig. 5a). These differences correlated with all essential amino acids being present among the subunits that form the hemoglobins in most mammals including pigs, rats and birds, whereas all subunits forming the nonfetal hemoglobins in primates including humans and even-toed ungulates such as cows and sheep lack isoleucine [87, 88] (Additional file 1: Table S3). Adding isoleucine but not select other essential amino acids to human and cow hemoglobin increased yolk deposition into oocytes to similar levels as pig hemoglobin (Fig. 5b). Feeding females blood cells from cow or sheep resulted in no eggs being laid, but adding isoleucine resulted in females laying similar numbers of eggs as occurred when females were fed whole blood or plasma (Fig. $5 \mathrm{c}$ ).

\section{Select other proteins also support egg formation}

We assessed whether any other commonly available proteins that are soluble in PBS at $200 \mathrm{mg} / \mathrm{ml}$ also stimulate Ae aegypti to deposit yolk into oocytes. The metalloenzyme carbonic anhydrase is produced in a variety of vertebrate tissues including bovine erythrocytes from which it is purified for commercial sale [89]. This protein and ovalbumin from chicken eggs stimulated yolk deposition, but duck ovalbumin, porcine gelatin and reconstituted skimmed milk powder from cows, which consists primarily of casein [90], did not (Fig. 6a). Sucrose in PBS-containing ATP, lipid (partially hydrogenated vegetable oil) in PBS plus ATP or PBS plus ATP alone were consumed and taken into the midgut by females but little or no yolk was deposited into oocytes (Fig. 6a). Since serum albumins load both fatty acids and steroids [91, 92], we compared females that consumed delipidated or a lipid-enriched BSA (Albumax II) versus standard fraction V BSA. No differences in yolk deposition were detected among these treatments but the number of eggs females laid were highest for females fed delipidated BSA (Fig. 6b). In contrast, females fed standard fraction V BSA digested into peptides using proteinase $\mathrm{K}$ or free amino acids at equivalent molarities to BSA at $200 \mathrm{mg} / \mathrm{ml}$ stimulated no yolk deposition (Fig. 6c). Several commercially available peptide mixtures (Proteose Peptone 3, Bacto Peptone and Casein Acid Hydrolysate) in PBS plus ATP were also readily consumed by females but stimulated no yolk deposition (Fig. 6c).

\footnotetext{
(See figure on next page.)

Fig. 3 Feeding and egg laying by An. gambiae in response to vertebrate blood and blood fractions. Females were provided whole blood, plasma or blood cells from four vertebrates. Bar graphs on the left indicate the proportion of females that fed to repletion, with sample size (i.e., the number of individuals offered the meal) indicated below the $x$-axis in italics. Statistical significance after contingency table analysis is indicated $\left({ }^{*} p<0.05\right.$; ${ }^{*} p$ $<0.001 ;{ }^{* * *} p<0.0001 ;$ ns not significant). Dot plots on the right show the number of eggs laid by replete females, with sample sizes (i.e., number of replete females obtained from the feeds on the left panel) indicated below the $x$-axis and horizontal bars showing the treatment mean \pm SD. Small case letters indicate treatments that significantly differed from one another after a Kruskal-Wallis and post-hoc Dunn's test ( $p \leq 0.05$ )
} 
Anopheles gambiae

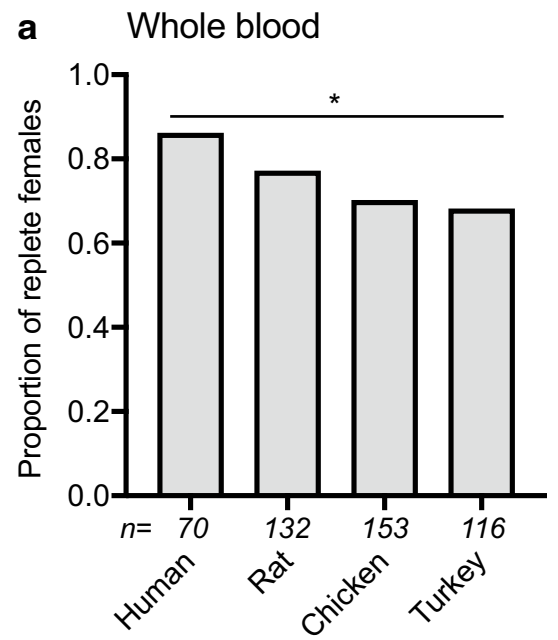

b Whole blood
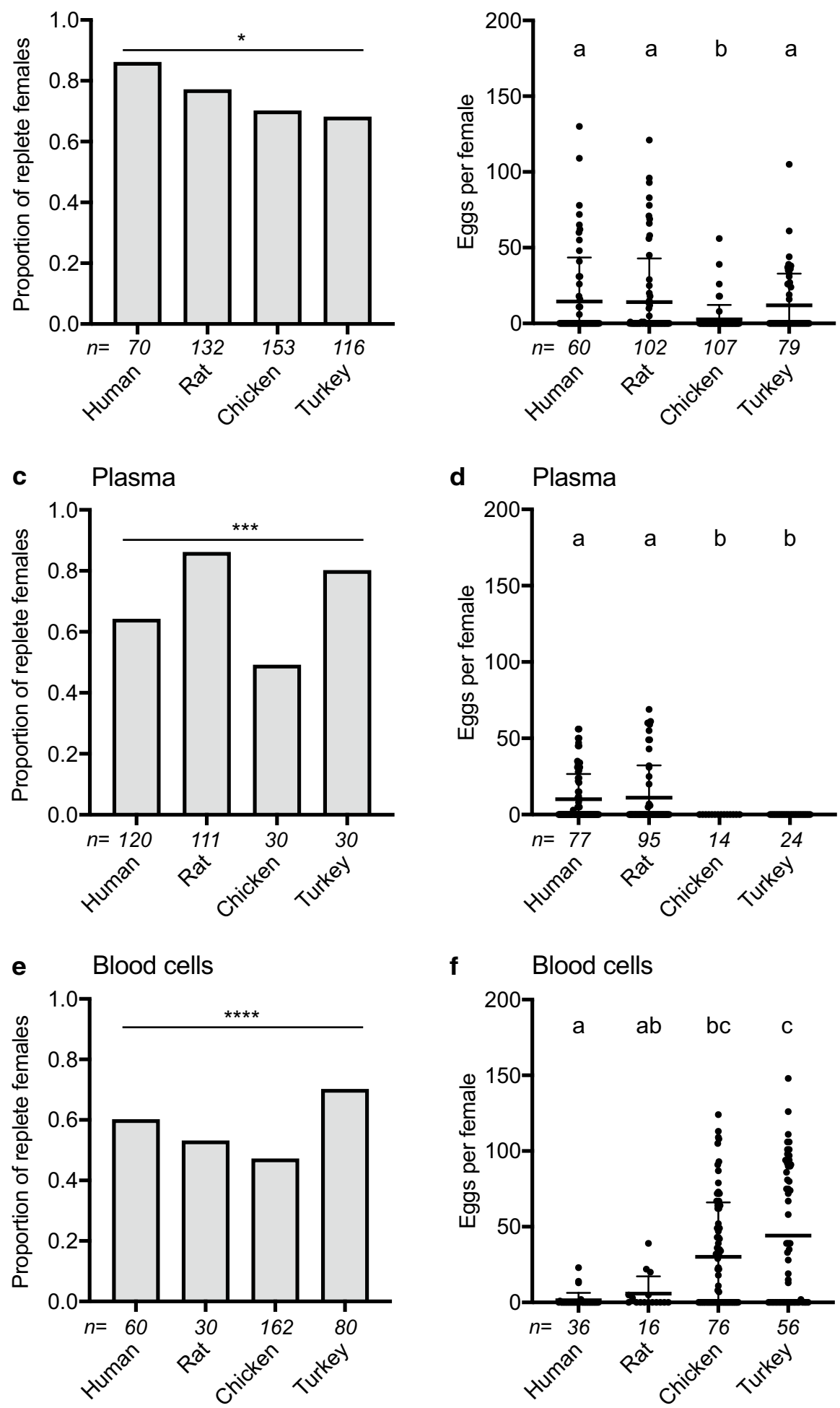


\section{Culex quinquefasciatus}

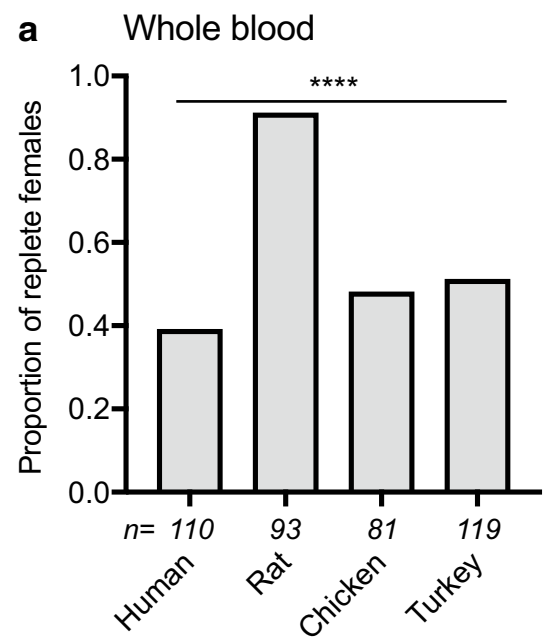

b Whole blood

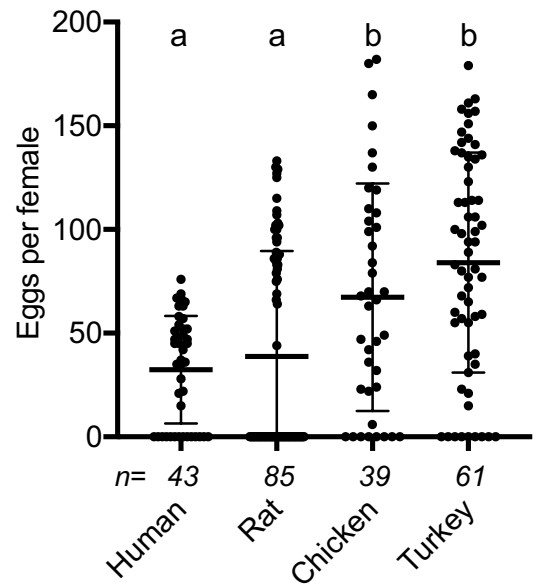

c Plasma

d Plasma
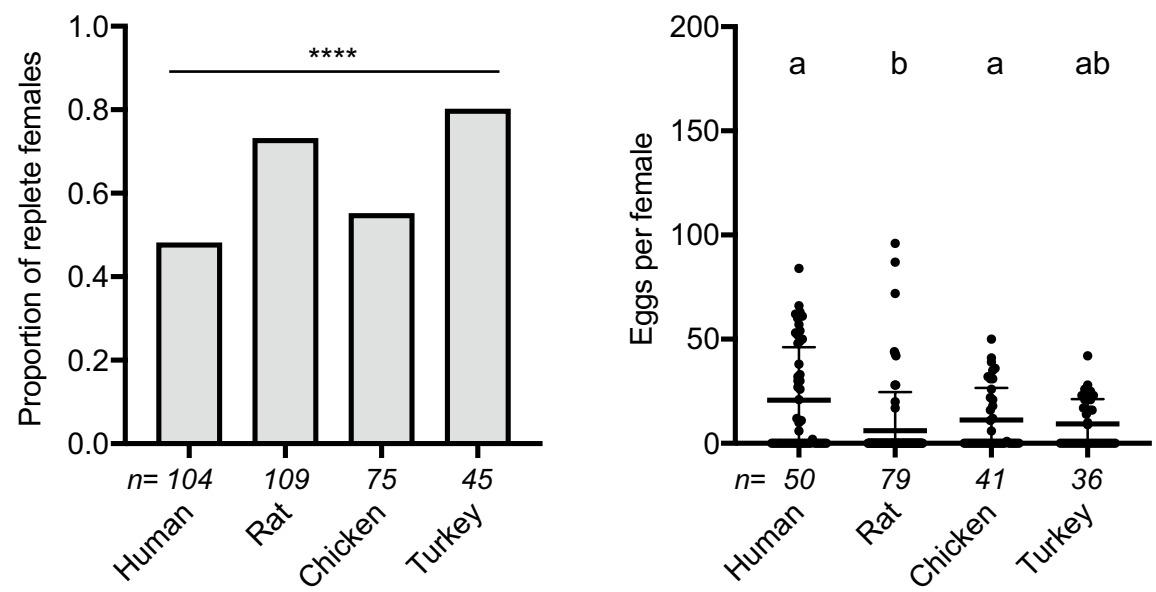

e Blood cells

f Blood cells
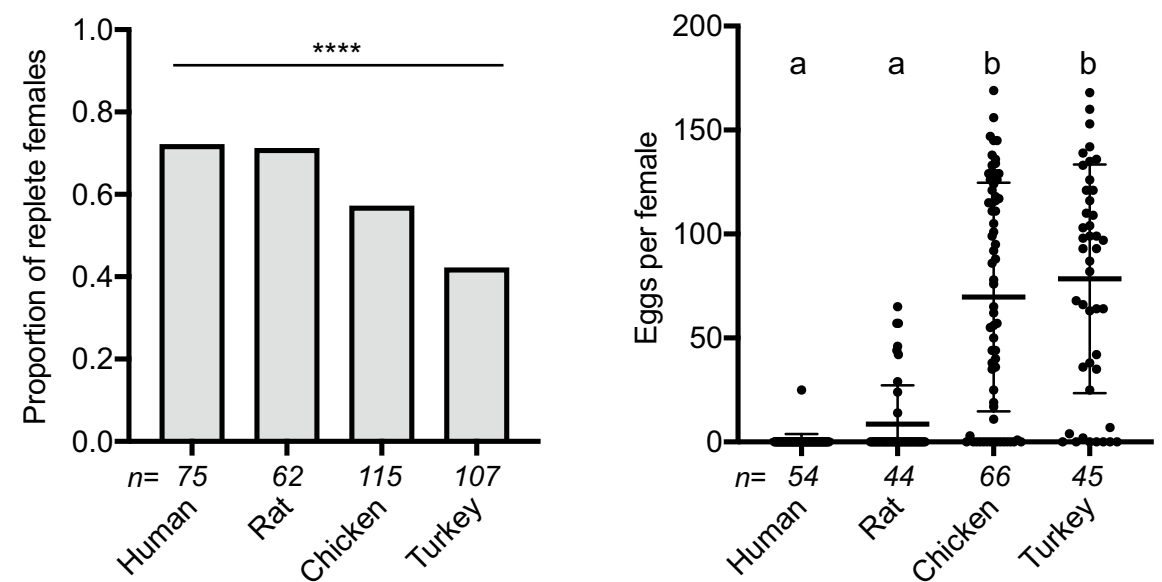

Fig. 4 Feeding and egg laying by C. quinquefasciatus in response to vertebrate blood and blood fractions. Data are presented as in Figs. 2 and 3, with proportions of females fed to repletion indicated in $\mathbf{a}, \mathbf{c}$ and $\mathbf{e}$ and egg clutch size per replete female shown in $\mathbf{b}$, $\mathbf{d}$ and $\mathbf{f}$. Italicized numbers below the $x$-axis indicate sample sizes, and statistical significances are indicated as previously described in the legends of Figs. 2 and 3 
BSA more weakly stimulated trypsin-like activity in the midgut yet comparably stimulated ecdysteroid production by the ovaries compared to blood

As previously noted, bloodmeal consumption by $A e$. aegypti females stimulates OEH and ILP release from the brain, which regulates bloodmeal digestion by the midgut and ecdysteroid production by the ovaries, which are both essential for egg formation [12-14]. Twelve trypsin-like serine protease (SP) genes are expressed in the midgut with prior studies identifying four (Aa5G1, AaLT, AaSPVI and AaSPVII) as latephase SPs that are inducibly expressed by blood feeding and are primarily responsible for bloodmeal digestion [12-14]. AaSPVI accounts for most late-phase trypsinlike activity [12-14]. With the potential exception of pig hemoglobin, yolk deposition was more strongly stimulated by BSA than any other blood protein we bioassayed. We therefore asked if BSA induced both high expression of late phase SPs and trypsin-like activity in the midgut, as does whole blood. We also bioassayed females that consumed BSA-derived peptides and the amino acid solution that mimicked the amino acid composition of BSA since neither induced any yolk deposition. BSA induced upregulation of Aa5G1, AaLT, AaSPVI and AaSPVII, ranging from 20 to 50 times higher relative to peptide-, amino acid- and non-fed females (Fig. 7a). However, expression of these serine proteases was not statistically different among these treatments, in contrast to whole blood, which induced 100-200 times higher expression of these genes relative to non-fed controls (Fig. 7a). BSA also stimulated late trypsin-like activity, but more weakly than whole blood, while no trypsin activity was detected in the midguts of females that consumed peptides or amino acids (Fig. 7b). In contrast, blood and BSA similarly stimulated the ovaries to produce ecdysteroids while peptides and amino acids did not (Fig. 7c).

\section{Discussion}

It has long been recognized that anautogenous mosquitoes blood feed to reproduce [27, 93, 94]. Studies dating back to the 1920s have examined different aspects of how vertebrate blood affects egg formation. However, as noted earlier, most papers in the literature focus on single species of mosquitoes and hosts. Thus, the primary novelty of this study is our comparative approach under standardized assay conditions that examined how: (i) three anautogenous species respond to blood and blood fractions from different vertebrates and (ii) purified blood proteins from different vertebrates affect egg formation and key physiological processes that regulate vitellogenesis in Ae. aegypti.

Several laboratory cultures of Ae. aegypti including the UGAL strain produce large clutches of eggs after feeding on rat and other rodent bloods, which underlies the common use of these mammals in general rearing [56, $95,96]$. In this study, we identified no differences in egg production between UGAL Ae. aegypti that feed on a living rat versus membrane feeders containing whole rat blood unless EDTA was used as an anticoagulant. We thus standardized subsequent assays by using membrane feeders and $\mathrm{Na}$ citrate as the anticoagulant. While summaries of the older literature conclude that anautogenous mosquitoes produce more eggs after feeding on vertebrates with nucleated erythrocytes $[36,53]$, only $C$. quinquefasciatus showed evidence of this in our results. Since C. quinquefasciatus preferentially feeds on birds in the field [83, 84, 97], this species may reproductively benefit from avian bloods, which has also been noted for other Culex species [30, 32, 33, 35, 98-102]. In contrast, anthropophilic Ae. aegypti and An. gambiae largely laid similar numbers of eggs across the two mammal and avian blood sources we tested. Our finding that $A e$. aegypti and An. gambiae did not lay more eggs when fed avian blood could reflect an adaptation of our laboratory cultures to mammalian blood, as both species have been reared exclusively on mammalian blood for hundreds of generations. Another possibility is that mosquitoes fed on living hosts are more strongly attracted to odorant and tactile cues from avian hosts and therefore imbibe larger bloodmeals resulting in larger egg clutches. Our artificial membrane feeders are devoid of such cues that might encourage excessive gorging in females.

\footnotetext{
(See figure on next page.)

Fig. 5 Yolk deposition into oocytes and egg laying by Ae. aegypti in response to blood proteins from different vertebrates. a Mean yolk length \pm SD $48 \mathrm{~h}$ after feeding to repletion on blood-derived proteins in PBS-containing ATP from different vertebrates. Each protein was fed to females at $200 \mathrm{mg}$ per $\mathrm{ml}$ with whole blood from a rat serving as the positive control and PBS containing ATP serving as the negative control. Small case letters indicate treatments significantly differed from one another after a Kruskal-Wallis and post-hoc Dunn's test ( $p \leq 0.05)$. b Mean yolk length \pm SD $48 \mathrm{~h}$ after feeding to repletion on cow or human hemoglobin with no additional amino acid (AA) or with addition of isoleucine (lle), leucine (Leu), arginine (Arg), methionine (Met) or tryptophan (Trp). Within each graph different small case letters indicate treatments significantly differed from one another after a Kruskal-Wallis and post-hoc Dunn's test $(p \leq 0.05)$. c Eggs laid per female after feeding to repletion on whole blood, plasma, blood cells or blood cells plus isoleucine from cow or sheep. Numbers above each treatment indicate the total number of replete females Horizontal bars indicate the mean \pm SD. Within each graph different small case letters indicate treatments significantly differed from one another after a Kruskal-Wallis and post-hoc Dunn's test $(p \leq 0.05)$
} 


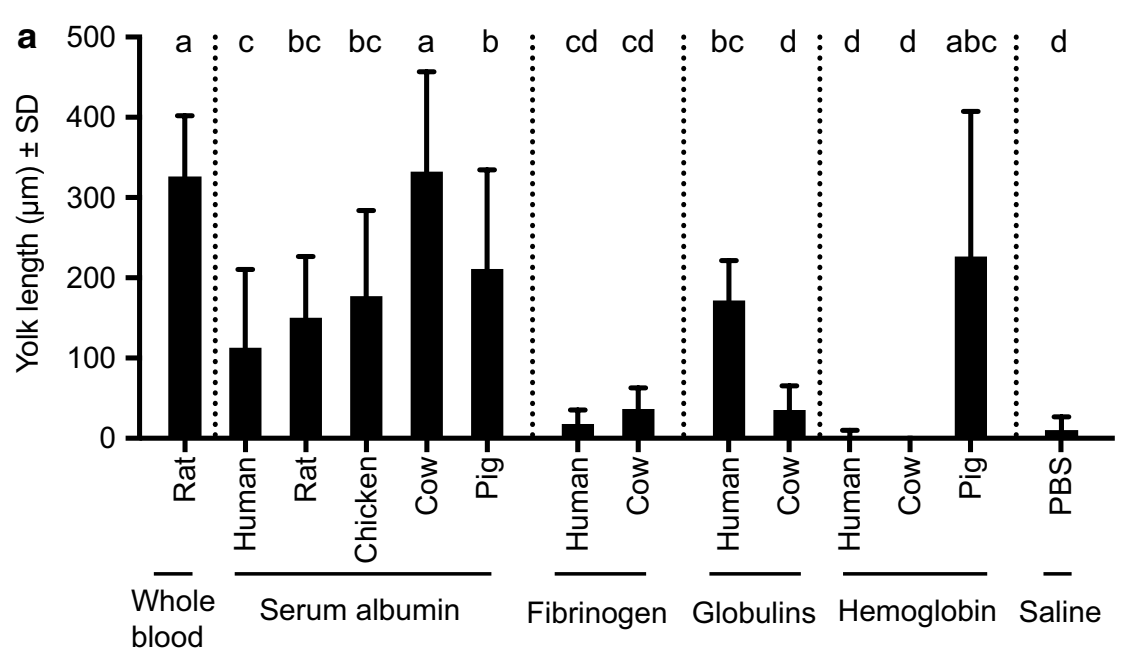

b Cow hemoglobin

Human hemoglobin
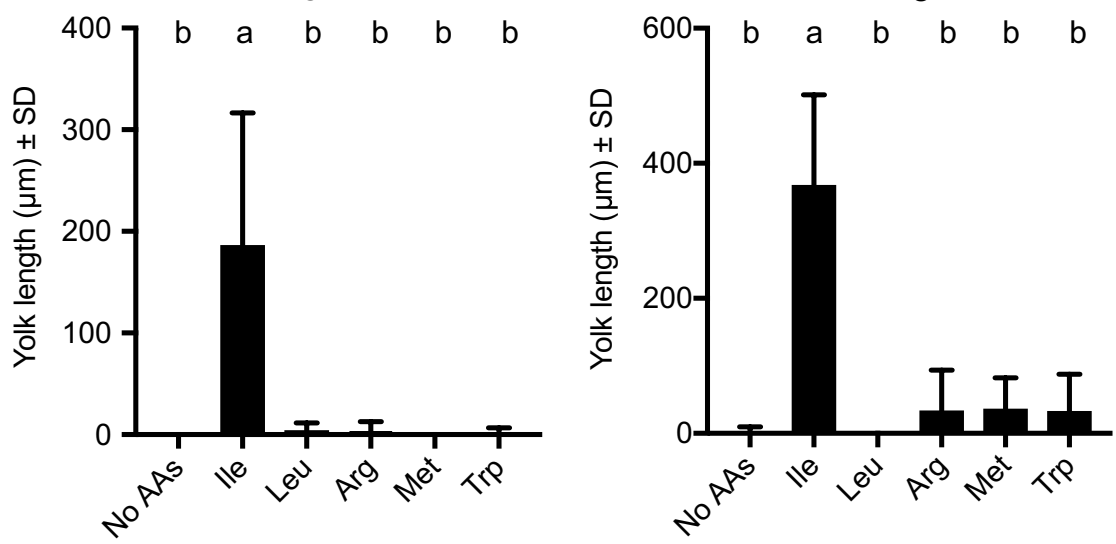

C Cow blood fractions

\section{Sheep blood fractions}
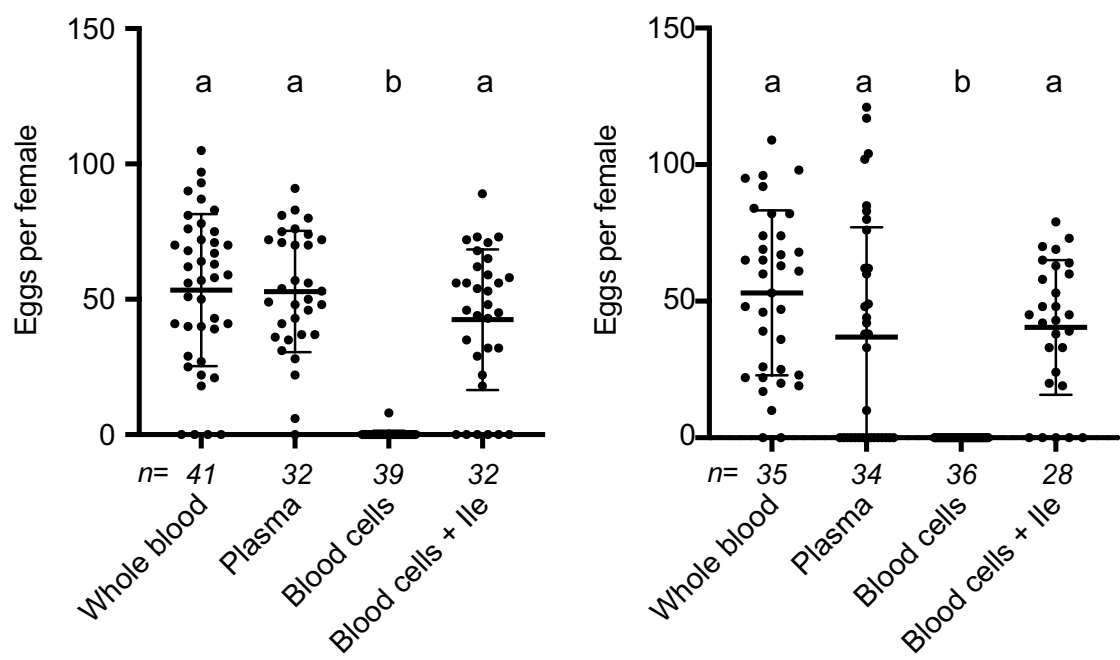
Contrary to other studies [31, 36, 56, 96, 103], our results show no evidence that Ae. aegypti and An. gambiae lay smaller clutches after feeding to repletion on whole human blood versus blood from other hosts. However, our results do show dramatic differences in egg formation in response to blood fractions with $A e$. aegypti and An. gambiae laying eggs after consuming mammalian but not avian plasmas. Avian blood cells further stimulated all three mosquito species to lay similar numbers of eggs as whole blood, while human blood cells resulted in females laying few or no eggs. Yet, in the case of $C$. quinquefasciatus, all plasmas stimulated females to lay similar, albeit lower, numbers of eggs than whole blood, while Ae. aegypti laid large numbers of eggs after consuming rat blood cells but $A n$. gambiae did not. Thus, each of the mosquito species we tested exhibited differences in egg laying across the four vertebrate bloods we tested but the two anthropophiles, Ae. aegypti and An. gambiae, overall exhibited more similarities to one another than to the ornithophile C. quinquefasciatus.

We focused the second part of our study on assessing how the major protein constituents of plasma and blood cells from different vertebrates differentially affect egg formation in Ae. aegypti. Pilot experiments revealed that $A n$. gambiae and $C$. quinquefasciatus fed poorly when offered meals containing solubilized serum albumins. The response of anopheline species to adenosine nucleotides as phagostimulants is a subject which requires further investigation; we propose that poor feeding on artificial meals not containing blood or blood fractions could be the result of a decreased response to our chosen phagostimulant (ATP) compared to Ae. aegypti. In addition to poor feeding, $A n$. gambiae in particular exhibited poor survival and viability following serum albumin ingestion. Given these confounding factors, and given that a more expansive molecular toolkit exists for the model organism Ae. aegypti, we chose not to use An. gambiae or C. quinquefasciatus in our studies of how purified blood proteins affect egg formation and the physiological processes that regulate vitellogenesis.

Hemoglobin accounts for $\sim 90 \%$ of the total protein in vertebrate blood and thus is far more abundant than any plasma protein [54]. We therefore standardized the concentration of each protein we tested $(200 \mathrm{mg} / \mathrm{ml})$ in feeding assays to reflect total protein in human blood rather than the actual abundance of each component. As previously noted, several studies report that BSA and whole blood comparably stimulate yolk deposition into primary follicles [67-74]. In contrast, our results show that serum albumins from other vertebrates more weakly stimulate yolk deposition than BSA, which was unanticipated given: (i) lyophilized plasmas of several mammals were recently reported to stimulate highlevel egg production in Ae. aegypti [66] and (ii) mammalian serum albumins share high amino acid identity (74-76\%) and have similar crystal structures [104, 105]. Our results further indicate that fibrinogens and globulins from two mammals (human, cow) stimulate low rates of yolk deposition. In contrast, hemoglobin from pig stimulates similar yolk deposition rates to whole rat blood and BSA while human and cow hemoglobin stimulates no yolk deposition. Thus, our results indicate that purified blood proteins differentially stimulate yolk deposition and that UGAL Ae. aegypti also differentially respond to homologs of the same protein from different vertebrates. That chicken ovalbumin stimulates yolk deposition indicates certain proteins absent in vertebrate blood can stimulate egg formation. Other studies also report variable oogenic responses by different mosquito species fed egg albumin, gelatin, skim milk, agar, soy infant formula and hemolymph from other insects [55, 62, 106-110].

Since albumins bind a range of lipids and other ligands $[91,111]$, we reasoned this variable potentially contributes to the differences in yolk deposition we see among vertebrate albumins. A previous study also

\footnotetext{
(See figure on next page.)

Fig. 6 Yolk deposition into oocytes and egg laying by Ae. aegypti in response to non-blood proteins and other factors. a Mean yolk length \pm SD $48 \mathrm{~h}$ after feeding to repletion on non-blood proteins, skim milk, sucrose or vegetable oil in PBS containing ATP. Each protein was fed to females at $200 \mathrm{mg} / \mathrm{ml}$ while other components were fed at concentrations as indicated in "Methods". PBS containing ATP served as the negative control. Small case letters indicate treatments significantly differed from one another after a Kruskal-Wallis and post-hoc Dunn's test $(p \leq 0.05)$. b Mean yolk length \pm SD 48 h or numbers of eggs laid per female after feeding to repletion on BSA, fatty acid depleted BSA or fatty acid-enriched (AlbuMAX II) BSA. For yolk length no significant difference (ns) was detected among treatments after a Kruskal-Wallis test $(p>0.05)$. For eggs per female, numbers above each treatment indicate the total number of replete females, horizontal bars indicate the mean $\pm S D$, and different small case letters indicate treatments significantly differed from one another after a Kruskal-Wallis and post-hoc Dunn's test $(p \leq 0.05)$. c Mean yolk length \pm SD $48 \mathrm{~h}$ after feeding to repletion on BSA, peptides derived from BSA, other peptide preparations or amino acids that mimic abundance in BSA. Each treatment was fed to females at $200 \mathrm{mg}$ per $\mathrm{ml}$. Small case letters indicate treatments significantly differed from one another after a Kruskal-Wallis and post-hoc Dunn's test ( $p \leq 0.05$ )
} 


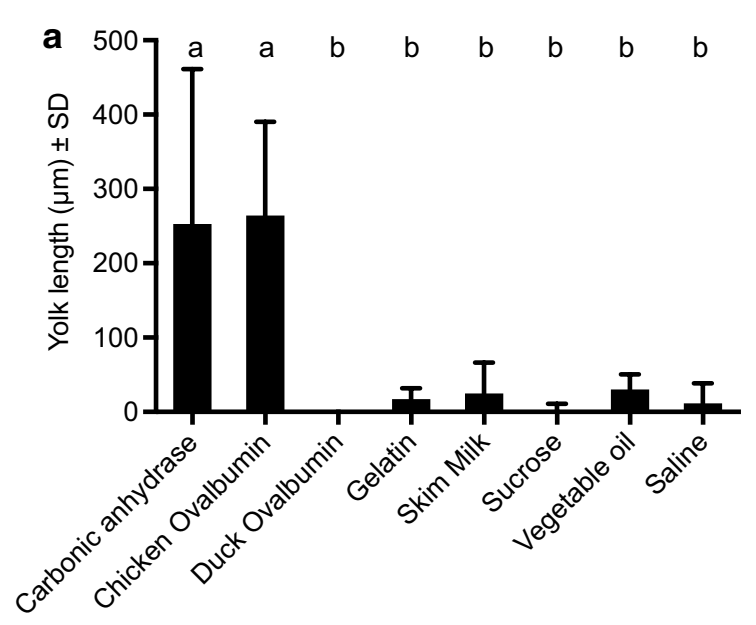

b
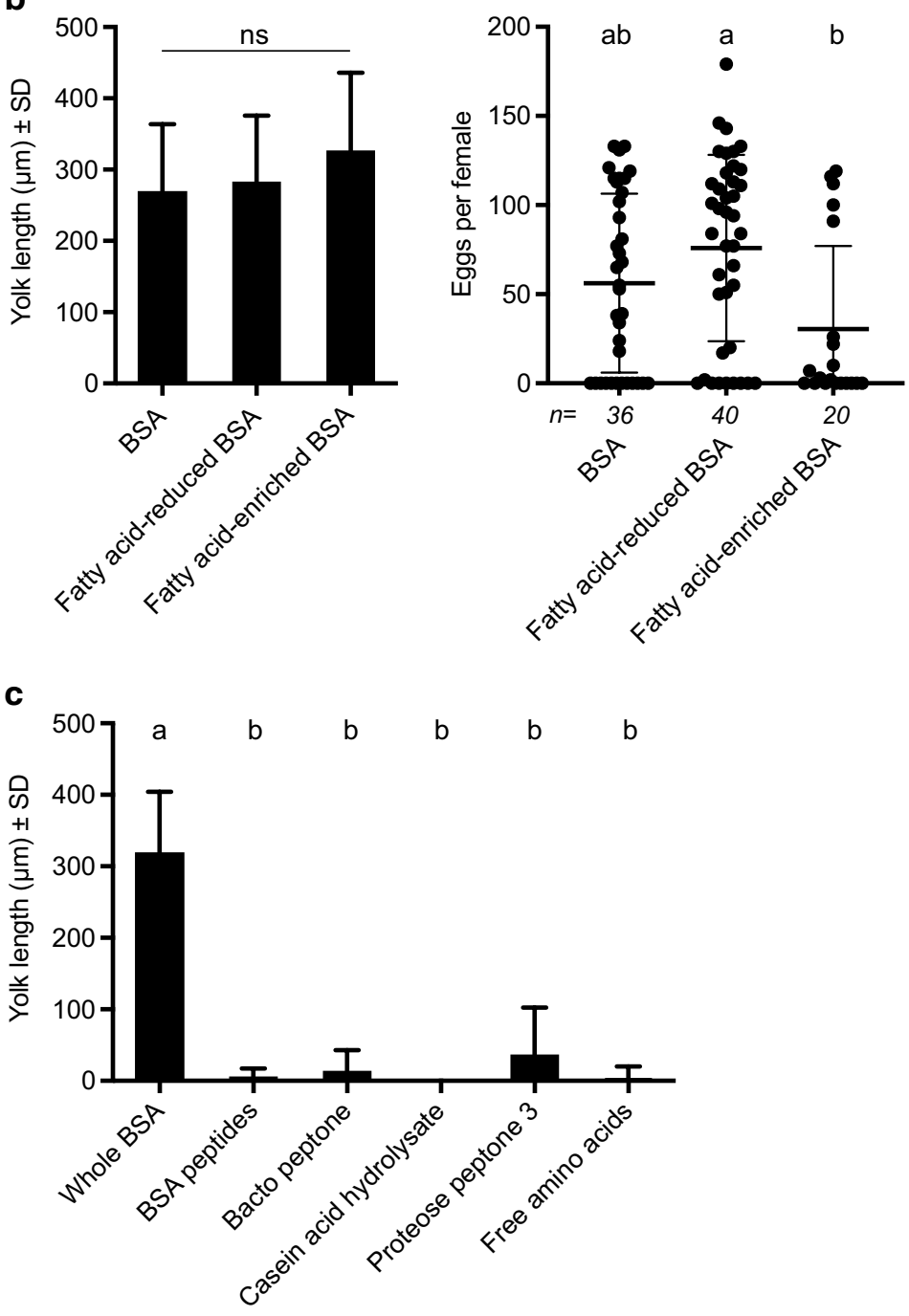
reported that addition of LDL and cholesterol to a BSAbased artificial diet increased fecundity in Ae. aegypti [70]. However, we detected no differences in yolk deposition between BSAs enriched or depleted for bound lipids and lipid-enriched BSA resulted in females laying fewer eggs. It is nevertheless possible that factors binding to serum albumins potentially contribute to the between-species differences in albumins we observed. On the other hand, our finding that females produce no mature eggs after consuming BSA-derived peptides, peptides from other proteins or free amino acids mimicking the composition of BSA suggest proteins must be of a minimum size for digestion and absorption and that small peptides and amino acids are potentially excreted too rapidly to be efficiently absorbed. This suggestion would also be consistent with studies showing that slow, continuous perfusion of essential amino acids into the hemocoel of mosquitoes promotes egg formation while single injections of amino acids do not $[52,108,112]$. We also note that our findings are not wholly in accord with two early reports that peptides and amino acids stimulated very low-level, but nonzero, egg formation in Ae. aegypti [113, 114].

Previous studies noted that isoleucine deficiencies in the blood of certain vertebrates correlate with reductions in egg production by anautogenous mosquitoes $[51,54,103]$. In contrast, our use of purified proteins definitively indicates that Ae. aegypti produces no mature eggs when fed hemoglobins lacking isoleucine but large numbers of eggs when fed hemoglobins that contain the essential amino acid isoleucine or when fed an isoleucine-deficient hemoglobin that is isoleucinesupplemented. The effect of isoleucine deficiency was previously attributed to essential amino acid balance being important for egg production $[51,55,96]$. However, amino acids function as nutritional signals in regulating a number of cellular processes through the TOR and insulin signaling pathways [115-117]. Amino acids also regulate translation initiation with the absence of any essential amino acid resulting in suppression of protein synthesis $[118,119]$. Thus, more complex mechanisms than amino acid balance likely underlie the severe defects in egg formation that occur when female mosquitoes feed on isoleucine-deficient hemoglobins.

Since BSA strongly stimulates egg formation in $\mathrm{Ae}$. aegypti, we asked if this protein and whole blood similarly stimulate two physiological processes required for vitellogenesis: late-stage serine protease gene expression in the midgut and ecdysteroid production by the ovaries. BSA did induce the expression of four proteases with known roles in bloodmeal digestion, Aa5G1, AaLT, AaSPVI and AaSPVII; however, levels of expression and trypsin-like activity were roughly half the levels measured in blood-fed females. Hundreds of serine proteases are expressed in Ae. aegypti [14], and midgut-localized proteases include not only trypsin-like enzymes but also chymotrypsins and two major classes of exopeptidases, aminopeptidases and carboxypeptidases [13, 120, 121]. Therefore, it is possible that BSA is primarily digested by enzymes other than the trypsin-like proteases we surveyed. In contrast, BSA and whole blood comparably stimulate ecdysteroid production by the ovaries, which is consistent with BSA and blood-fed females laying similar numbers of eggs $[65,68,71]$.

\section{Conclusions}

Three species of anautogenous mosquitoes variably produced eggs in response to whole vertebrate blood, blood fractions or specific proteins from different vertebrates. For the most abundant protein in blood, hemoglobin, major differences in egg formation by Ae. aegypti were clearly due to isoleucine deficiency of this protein from select vertebrates, whereas the underlying basis for serum albumins differentially affecting egg formation remained unclear. Physiological assays in Ae. aegypti further showed that blood and BSA differentially stimulate digestive enzyme activity but comparably stimulate ecdysteroidogenesis.

\footnotetext{
(See figure on next page.)

Fig. 7 Late-phase serine protease gene expression, midgut trypsin-like activity and ovary ecdysteroid production by Ae. aegypti after feeding on blood, BSA or BSA-derived products. a rqRT-PCR analysis of Aa5G1, AaLT, AaSPVI and AaSPVII expression in midguts 24 h after feeding to repletion on rat blood, BSA, BSA-derived peptides or amino acids that mimic abundance in BSA. Mean relative transcript abundance \pm SD for each treatment is normalized to the actin gene. Each treatment was replicated four times using midgut samples prepared from different females. Small case letters indicate treatments significantly differed from one another after ANOVA and a post-hoc Tukey-Kramer multiple comparison test ( $p \leq 0.05$ ). b Trypsin-like activity $24 \mathrm{~h}$ after the same treatments listed in (a). Non-fed females served as the negative control. Horizontal bars indicate the mean \pm SD. Small case letters indicate treatments significantly differed from one another after ANOVA and a post-hoc Tukey-Kramer multiple comparison test $(p \leq 0.05)$. c Ecdysteroids produced per ovary pair \pm SD from females that fed to repletion on the same treatments as in (a). Ovaries were collected from females at $24 \mathrm{~h}$ post-feeding and ecdysteroid amounts determined by EIA after a $6 \mathrm{~h}$ incubation in saline. A minimum of ten independent samples were prepared per treatment with different letters indicating significant differences after ANOVA and a post-hoc Tukey-Kramer multiple comparison test $(p \leq 0.05)$
} 
I. I

I.

脑 


\section{Supplementary Information}

The online version contains supplementary material available at https://doi. org/10.1186/s13071-021-04594-9.

Additional file 1: Table S1. Amino acid amounts added to PBS to equal their abundance in BSA at $200 \mathrm{mg} / \mathrm{ml}$. Table S2. Proportion of hatching eggs for mosquitoes fed whole blood or fractions from four vertebrate hosts. Table S3. Amino acid compositions of major hemoglobin subunits of adult-stage vertebrates.

\section{Abbreviations}

20E: 20-Hydroxyecdysone; AA: Amino acid; ATP: Adenosine triphosphate; BSA: Bovine serum albumin; ECD: Ecdysone; EDTA: Ethylenediaminetetraacetic acid; EIA: Enzyme-linked immunosorbent assay; ILP: Insulin-like peptide; IR: Insulin receptor; OEH: Ovary ecdysteroidogenic hormone; OEHR: OEH receptor; PBS: Phosphate-buffered saline; SD: Standard deviation; SP: Serine protease; TOR: Target of rapamycin; Vg: Vitellogenin.

\section{Acknowledgements}

We thank Jena A. Johnson, Jaron Brandt Singco, Lilith South and Severen Brown for maintenance of the Ae. aegypti, An. gambiae and C. quinquefasciatus cultures from which adult females were taken for these experiments. Jena A. Johnson also designed Fig. 1.

\section{Authors' contributions}

REH participated in the conception of the study, data acquisition, data analysis and writing of the manuscript. MRB participated in conception and supervision of the study. MRS participated in conception and supervision of the study and in writing of the manuscript. All authors read and approved the final manuscript.

\section{Funding}

This work was supported by the National Institutes of Health R01Al106892 (MRS and MRB) and R01AI033108 (MRS). REH was also partially supported by National Institutes of Health training grant T32Al060546.

\section{Availability of data and materials}

All essential data for this study are presented in the main text and supplementary information section. Data sets are freely available from the corresponding author upon request.

\section{Ethics approval and consent to participate}

Laboratory rats were maintained and used for blood feeding of Ae. aegypti and C. quinquefasciatus colonies under Animal Use Protocol A2018 02-002Y1-AO, which was approved by The University of Georgia Institutional Animal Care and Use Committee (IACUC). The UGA IACUC oversees and provides veterinary care for all campus animal care facilities and is licensed by the US Department of Agriculture (USDA) and maintains an animal welfare assurance, in compliance with Public Health Service policy, through the NIH Office of Laboratory Animal Welfare, and registration with the USDA APHIS Animal Care, in compliance with the USDA Animal Welfare Act and Regulations, 9 CFR. IACUC personnel attend to all rodent husbandry under strict guidelines to insure careful and consistent handling. The University of Georgia's animal use policies and operating procedures facilitated compliance with applicable federal regulations, guidance, and state laws governing animal use in research and teaching including the: (i) Animal Welfare Act, (ii) Public Health Service (PHS) Policy on the Humane Care and Use of Laboratory Animals, (iii) United States Government Principles for the Utilization and Care of Vertebrate Animals Used in Testing, Research and Training, (iv) Guide for the Care and Use of Laboratory Animals, (v) Guide for the Care and Use of Agricultural Animals in Research and Teaching, (vi) American Veterinary Medical Association Guidelines for the Euthanasia of Animals and (vii) Applicable Georgia laws. No human subjects or tissue were used in this study.

\section{Consent for publication}

Not applicable.

\section{Competing interests}

The authors declare that they have no competing interests.

Received: 3 November 2020 Accepted: 11 January 2021 Published online: 24 February 2021

\section{References}

1. World Health Organization. A global brief on vector-borne diseases Geneva: World Health Organization; 2014.

2. Foster WA. Mosquito sugar feeding and reproductive energetics. Annu Rev Entomol. 1995:40:443-74.

3. Barredo E, DeGennaro M. Not Just from blood: mosquito nutrient acquisition from nectar sources. Trends Parasitol. 2020;36(5):473-84.

4. Clements AN. The biology of mosquitoes: development, nutrition and reproduction. London: Chapman \& Hall; 1992.

5. Valzania L, Mattee MT, Strand MR, Brown MR. Blood feeding activates the vitellogenic stage of oogenesis in the mosquito Aedes aegypti through inhibition of glycogen synthase kinase 3 by the insulin and TOR pathways. Dev Biol. 2019;454(1):85-95.

6. Roy S, Smykal V, Johnson L, Saha T, Zou Z, Raikhel A. Regulation of reproductive processes in female mosquitoes. Adv Insect Physiol. 2016:51:115-44.

7. Brown MR, Clark KD, Gulia M, Zhao Z, Garczynski SF, Crim JW, et al. An insulin-like peptide regulates egg maturation and metabolism in the mosquito Aedes aegypti. Proc Natl Acad Sci U S A. 2008;105(15):5716-21.

8. Dhara A, Eum JH, Robertson A, Gulia-Nuss M, Vogel KJ, Clark KD, et al. Ovary ecdysteroidogenic hormone functions independently of the insulin receptor in the yellow fever mosquito Aedes aegypti. Insect Biochem Mol Biol. 2013:43(12):1100-8.

9. Vogel KJ, Brown MR, Strand MR. Ovary ecdysteroidogenic hormone requires a receptor tyrosine kinase to activate egg formation in the mosquito Aedes aegypti. Proc Natl Acad Sci U S A. 2015;1 12(16):5057-62.

10. McKinney DA, Eum JH, Dhara A, Strand MR, Brown MR. Calcium influx enhances neuropeptide activation of ecdysteroid hormone production by mosquito ovaries. Insect Biochem Mol Biol. 2016;70:160-9.

11. Hagedorn H, Oconnor J, Fuchs MS, Sage B, Schlaeger DA, Bohm M. The ovary as a source of alpha-ecdysone in an adult mosquito. Proc Natl Acad Sci. 1975;72(8):3255-9.

12. Briegel H. Physiological bases of mosquito ecology. J Vector Ecol. 2003;28:1-11.

13. Isoe J, Rascon AA Jr, Kunz S, Miesfeld RL. Molecular genetic analysis of midgut serine proteases in Aedes aegypti mosquitoes. Insect Biochem Mol Biol. 2009;39(12):903-12.

14. Brackney DE, Isoe J, Black W IV, Zamora J, Foy BD, Miesfeld RL, et al. Expression profiling and comparative analyses of seven midgut serine proteases from the yellow fever mosquito, Aedes aegypti. J Insect Physiol. 2010;56(7):736-44.

15. Gulia-Nuss M, Robertson AE, Brown MR, Strand MR. Insulin-like peptides and the target of rapamycin pathway coordinately regulate blood digestion and egg maturation in the mosquito Aedes aegypti. PLoS ONE. 2011;6(5):e20401.

16. Hansen IA, Attardo GM, Rodriguez SD, Drake LL. Four-way regulation of mosquito yolk protein precursor genes by juvenile hormone-, ecdysone-, nutrient-, and insulin-like peptide signaling pathways. Front Physiol. 2014;5:103.

17. Raikhel AS, Dhadialla TS. Accumulation of yolk proteins in insect oocytes. Annu Rev Entomol. 1992;37:217-51.

18. Briegel H, Gut T, Lea A. Sequential deposition of yolk components during oogenesis in an insect, Aedes aegypti (Diptera: Culicidae). J Insect Physiol. 2003;49(3):249-60.

19. De Smet WH. The total protein content in the blood serum of 416 species and subspecies of. Acta Zoo Pathol Antverpiensia. 1978;70:35-56.

20. Wintrobe MM. Variations in the size and hemoglobin content of erythrocytes in the blood of various vertebrates. Folia Haematol. 1934;51(32):32-49.

21. Hawkey CM, Bennett PM, Gascoyne SC, Hart MG, Kirkwood JK. Erythrocyte size, number and haemoglobin content in vertebrates. $\mathrm{Br} J$ Haematol. 1991;77(3):392-7. 
22. Snyder GK, Sheafor BA. Red blood cells: centerpiece in the evolution of the vertebrate circulatory system. Am Zool. 1999;39(2):189-98.

23. Etim N, Williams ME, Akpabio U, Offiong EE. Haematological parameters and factors affecting their values. Agric Sci. 2014;2(1):37-47.

24. Harrington LC, Edman JD, Scott TW. Why do female Aedes aegypti (Diptera: Culicidae) feed preferentially and frequently on human blood? J Med Entomol. 2001;38(3):411-22.

25. Lyimo IN, Ferguson HM. Ecological and evolutionary determinants of host species choice in mosquito vectors. Trends Parasitol. 2009;25(4):189-96.

26. Lyimo IN, Keegan SP, Ranford-Cartwright LC, Ferguson HM. The impact of uniform and mixed species blood meals on the fitness of the mosquito vector Anopheles gambiae s.s: does a specialist pay for diversifying its host species diet? J Evol Biol. 2012;25(3):452-60.

27. Gordon R. Notes on the bionomics of stegomyia calopus, Meigen, in Brazil: Part II. Ann Trop Med Parasitol. 1922;16(4):425-39.

28. Tate $P$, Vincent $M$. The biology of autogenous and anautogenous races of Culex pipiens L. (Diptera: Culicidae). Parasitology. 1936;28(1):115-45.

29. Woke P. Cold-Blooded Vertebrates as Hosts for Aëdes aegypti Linn. J Parasitol. 1937:23(3):310-1.

30. Jordan HB. The effects of the quality of blood and temperature on the production and viability of eggs in Culex qunquefasciatus. Mosquito News. 1961;21(2):133-5.

31. Bennett GF. The influence of the blood meal type on the fecundity of Aedes (Stegomyia) aegypti L. (Diptera: Culicidae). Can J Zool. 1970;48(3):539-43.

32. Shelton RM. The effects of blood source and quantity on production of eggs by Culex salinarius Coquillett (Diptera: Culicidae). Mosq News. 1972;31:31-7.

33. Shroyer D, Siverly R. A comparison of egg production of Culex pipiens pipiens $\mathrm{L}$. fed on avian and mammalian hosts. Mosq News. 1972;32:636-7.

34. Jalil M. Observations on the fecundity of Aedes triseriatus (Diptera: Culicidae). Entomol Exp Appl. 1974;17(2):223-33.

35. Downe AE, Archer JA. The effects of different blood-meal sources on digestion and egg production in Culex tarsalis Coq. (Diptera: Culicidae). J Med Entomol. 1975;12(4):431-7.

36. Nayar JK, Sauerman DM Jr. The effects of nutrition on survival and fecundity in Florida mosquitoes. Part 4. Effects of blood source on oocyte development. J Med Entomol. 1977;14(2):167-74.

37. Mather TN, DeFoliart GR. Effect of host blood source on the gonotrophic cycle of Aedes triseriatus. Am J Trop Med Hyg. 1983;32(1):189-93.

38. Ferdousi Z, Islam MS. Impacts of vertebrate blood meals on reproductive performance, female size and male mating competitiveness in the mosquito Culex quinquefasciatus Say (Diptera: Culicidae). J Life Earth Science. 2006;1(1):65-70.

39. Olayemi I, Ande A, Danlami G, Abdullahi U. Influence of blood meal type on reproductive performance of the Malaria vector Anopheles gambiae ss (Diptera: Culicidae). J Entomol. 2011;8:459-67.

40. Phasomkusolsil S, Tawong J, Monkanna N, Pantuwatana K, Damdangdee N, Khongtak W, et al. Maintenance of mosquito vectors: effects of blood source on feeding, survival, fecundity, and egg hatching rates. J Vector Ecol. 2013·38(1):38-45.

41. Shehata AZ. Feeding rate and reproductive performance of three mosquito species as influenced by different blood meal sources. Egypt Acad J Biol Sci. 2018;11(6):77-84.

42. Gunathilaka N, Ranathunge T, Udayanga L, Abeyewickreme W. Efficacy of blood sources and artificial blood feeding methods in rearing of Aedes aegypti (Diptera: Culicidae) for sterile insect technique and incompatible insect technique approaches in Sri Lanka. Biomed Res Int. 2017;2017:3196924

43. Woke PA, Ally MS, Rosenberger CR Jr. The numbers of eggs developed related to the quantities of human blood ingested in Aedes aegypti (L.) (Diptera: Culicidae). Ann Entomol Soc. 1956;49(5):435-41.

44. Colless DH, Chellapah W. Effects of body weight and size of blood-meal upon egg production in Aedes aegypti (Linnaeus)(Diptera, Culicidae) Ann Trop Med Parasitol. 1960;54(4):475-82.

45. McCann S, Day JF, Allan S, Lord CC. Age modifies the effect of body size on fecundity in Culex quinquefasciatus Say (Diptera: Culicidae). J Vector Ecol. 2009;34(2):174-81.
46. Phasomkusolsil S, Pantuwattana K, Tawong J, Khongtak W, Kertmanee Y, Monkanna N, et al. The relationship between wing length, blood meal volume, and fecundity for seven colonies of Anopheles species housed at the Armed Forces Research Institute of Medical Sciences, Bangkok. Thailand Acta Trop. 2015;152:220-7.

47. Edman JD, Lynn HC. Relationship between blood meal volume and ovarian development in Culex nigripalpus (Diptera: Culicidae). Entomol Exp Appl. 1975;18(4):492-6.

48. Sen S. A preliminary note on the rôle of blood in ovulation in Culicidae. Indian J Med Res. 1917;4(4):729-53.

49. Yoeli M, Mer G. The relation of blood feeds to the maturation of ova in Anopheles elutus. Trans R Soc Trop Med Hyg. 1938;31(4):437-44.

50. Dimond J, Lea A, Hahnert W, DeLong D. The amino acids required for egg production in Aedes aegypti. Can Entomol. 1956;88(2):57-62.

51. Lea A, Dimond J, Delong D, editors. Some nutritional factors in egg production by Aedes aegypti. Proc 10th Int Congr Entomol; 1958.

52. Uchida K. Role of nutrition in initiation and promotion of ovarian development in the Japanese house mosquito, Culex pipiens pallens. Med Entomol Zool. 1998;49(2):75-85.

53. Clements A. The physiology of mosquitoes. 1st ed. Oxford: Pergamon Press; 1963. p. 393.

54. Briegel $\mathrm{H}$. Mosquito reproduction: incomplete utilization of the blood meal protein for oögenesis. J Insect Physiol. 1985;31(1):15-21.

55. Greenberg J. Some nutritional requirements of adult mosquitoes (Aedes aegypti) for oviposition. J Nutr. 1951;43(1):27-35.

56. Briegel H, Rezzonico L. Concentration of host blood protein during feeding by anopheline mosquitoes (Diptera: Culicidae). J Med Entomol. 1985;22(6):612-8

57. Vaughan JA, Noden BH, Beier JC. Concentrations of human erythrocytes by anopheline mosquitoes (Diptera: Culicidae) during feeding. J Med Entomol. 1991;28(6):780-6.

58. Shieh JN, Rossingnol PA. Opposite influences of host anaemia on blood feeding rate and fecundity of mosquitoes. Parasitology. 1992;105(Pt 2):159-63.

59. Taylor PJ, Hurd H. The influence of host haematocrit on the blood feeding success of Anopheles stephensi: implications for enhanced malaria transmission. Parasitology. 2001;122(Pt 5):491-6.

60. Emami SN, Ranford-Cartwright LC, Ferguson HM. The impact of low erythrocyte density in human blood on the fitness and energetic reserves of the African malaria vector Anopheles gambiae. Malaria J. 2013:12(1):1-10.

61. Woke P. Effects of various blood fractions on egg production of Aedes aegypti Linn. Am J Hyg. 1937:25(2):372-80.

62. Spielman A, Wong J. Dietary factors stimulating oogenesis in Aedes aegypti. Biol Bull. 1974;147(2):433-42.

63. Coluzzi M, Concetti A, Ascoli F. Effect of cibarial armature of mosquitoes (Diptera, Culicidae) on blood-meal haemolysis. J Insect Physiol. 1982;28(10):885-8.

64. Daniel TL, Kingsolver JG. Feeding strategy and the mechanics of blood sucking in insects. J Theor Biol. 1983;105(4):661-77.

65. Gonzales KK, Tsujimoto H, Hansen IA. Blood serum and BSA, but neither red blood cells nor hemoglobin can support vitellogenesis and egg production in the dengue vector Aedes aegypti. PeerJ. 2015;3:e938.

66. Baughman T, Peterson C, Ortega C, Preston SR, Paton C, Williams J, et al. A highly stable blood meal alternative for rearing Aedes and Anopheles mosquitoes. PLoS Negl Trop Dis. 2017;11(12):e0006142.

67. da Silva CG, Rodrigues MMS, Silva AdAe. Toward a blood-free diet for Anopheles darlingi (Diptera: Culicidae). J Med Entomol. 2020;57(3):947-51.

68. Gonzales KK, Rodriguez SD, Chung HN, Kowalski M, Vulcan J, Moore $E L$, et al. The effect of Skitosnack, an artificial blood meal replacement, on Aedes aegypti life history traits and gut microbiota. Sci Rep. 2018;8(1):11023.

69. Gonzales KK, Hansen IA. Artificial diets for mosquitoes. Int J Environ Res Public Health. 2016;13(12):1267.

70. Talyuli OA, Bottino-Rojas V, Taracena ML, Soares AL, Oliveira JH, Oliveira $\mathrm{PL}$. The use of a chemically defined artificial diet as a tool to study Aedes aegypti physiology. J Insect Physiol. 2015:83:1-7.

71. Pitts RJ. A blood-free protein meal supporting oogenesis in the Asian tiger mosquito, Aedes albopictus (Skuse). J Insect Physiol. 2014;64:1-6.

72. Kogan $\mathrm{PH}$. Substitute blood meal for investigating and maintaining Aedes aegypti (Diptera: Culicidae). J Med Entomol. 1990;27(4):709-12. 
73. Cosgrove JB, Wood RJ. Effects of variations in a formulated protein meal on the fecundity and fertility of female mosquitoes. Med Vet Entomol. 1996;10(3):260-4.

74. Sianturi LJ, Susapto D, Church CJ. Packed red blood cells and bovine serum albumin as a blood meal source for Anopheles farauti. J Am Mosa Control Assoc. 1996;12(4):730-1.

75. Powell JR, Tabachnick WJ. History of domestication and spread of Aedes aegypti_a review. Mem Inst Oswaldo Cruz. 2013;108(Suppl 1):11-7.

76. Galun R, Avi-Dor Y, Bar-Zeev M. Feeding response in Aedes aegypti: stimulation by adenosine triphosphate. Science. 1963;142(3600):1674-5.

77. Gulia-Nuss M, Eum J-H, Strand MR, Brown MR. Ovary ecdysteroidogenic hormone activates egg maturation in the mosquito George craigius atropalpus after adult eclosion or a blood meal. J Exp Biol. 2012;215(21):3758-67.

78. McKinney DA, Strand MR, Brown MR. Evaluation of ecdysteroid antisera for a competitive enzyme immunoassay and extraction procedures for the measurement of mosquito ecdysteroids. Gen Comp Endocrinol. 2017:253:60-9.

79. Dzaki N, Ramli KN, Azlan A, Ishak IH, Azzam G. Evaluation of reference genes at different developmental stages for quantitative real-time PCR in Aedes aegypti. Sci Rep. 2017;7:43618.

80. Livak KJ, Schmittgen TD. Analysis of relative gene expression data using real-time quantitative PCR and the $2-\triangle \triangle C T$ method. Methods. 2001;25(4):402-8

81. Yasrul RT, Umniyati SR, Mulyaningsih B, editors. The effect of anticoagulant on the feeding rate, mortality rate, and infection rate of Aedes aegypti (Diptera: Culicidae) orally infected with dengue virus-3. AIP Conference Proceedings; 2108, 020002 (2019): https://doi. org/10/1063/1.5109977.

82. Carde RT. Multi-cue integration: how female mosquitoes locate a human host. Curr Biol. 2015:25(18):R793-5.

83. Stone C, Gross K. Evolution of host preference in anthropophilic mosquitoes. Malaria J. 2018;17(1):257.

84. Asigau S, Salah S, Parker PG. Assessing the blood meal hosts of Culex quinquefasciatus and Aedes taeniorhynchus in Isla Santa Cruz, Galápagos. Parasites Vectors. 2019;12(1):1-10.

85. Adkins JN, Varnum SM, Auberry KJ, Moore RJ, Angell NH, Smith RD, et al. Toward a human blood serum proteome: analysis by multidimensional separation coupled with mass spectrometry. Mol Cell Proteomics. 2002;1(12):947-55.

86. Hardison RC. Evolution of hemoglobin and its genes. Cold Spring Harbor Perspect Med. 2012:2(12):a011627.

87. Dayhoff MO. Atlas of protein sequence and structure. Washington: National Biomedical Research Foundation; 1972.

88. Sherman I. Amino acid metabolism and protein synthesis in malarial parasites. Bull World Health Organ. 1977:55(2-3):265.

89. da Costa OJ, Sala L, Cerveira GP, Kalil SJ. Purification of carbonic anhydrase from bovine erythrocytes and its application in the enzymic capture of carbon dioxide. Chemosphere. 2012;88(2):255-9.

90. Lin Y, Kelly AL, O'Mahony JA, Guinee TP. Addition of sodium caseinate to skim milk increases nonsedimentable casein and causes significant changes in rennet-induced gelation, heat stability, and ethanol stability. J Dairy Sci. 2017;100(2):908-18.

91. van der Vusse GJ. Albumin as fatty acid transporter. Drug Metab Pharmacokinet. 2009:24(4):300-7.

92. Sankaranarayanan S, de la Llera-Moya M, Drazul-Schrader D, Phillips MC, Kellner-Weibel G, Rothblat GH. Serum albumin acts as a shuttle to enhance cholesterol efflux from cells. J Lipid Res. 2013:54(3):671-6.

93. Bacot AW. Report of the entomological investigation undertaken for the commission for the year, August 1914, to July, 1915. Yellow Fever Comm. 1916;3:1-191.

94. Fielding J. Notes on the bionomics of Stegomyia fasciata, Fabr (Part I). Ann Trop Med Parasitol. 1919;13(3):259-96.

95. Klowden MJ, Lea AO. Blood meal size as a factor affecting continued host-seeking by Aedes aegypti (L.). Am J Trop Med Hyg. 1978:27(4):827-31.

96. Chang $\mathrm{Y}-\mathrm{YH}$, Judson $\mathrm{CL}$. The role of isoleucine in differential egg production by the mosquito Aedes aegypti Linnaeus (Diptera: Culicidae) following feeding on human or guinea pig blood. Comp Biochem Physiol A Mol Integr Physiol. 1977;57(1):23-8.
97. Garcia-Rejon JE, Blitvich BJ, Farfan-Ale JA, Loroño-Pino MA, Chim WAC, Flores-Flores LF, et al. Host-feeding preference of the mosquito, Culex quinquefasciatus, in Yucatan State. Mexico J Insect Sci. 2010;10:32.

98. Roubaud É, Mezger J. Influence du sang d'oiseau sur la fécondité du moustique commun,"Culex pipiens L.": Masson; 1934. Bulletin de la Société de PathologieExotique, (27): 666-668.

99. Woke P. Comparative effects of the blood of man and of canary on eggproduction of Culex pipiens Linn. J Parasitol. 1937;23(3):311-3.

100. McCray E, Schoof HF. Laboratory behavior of Culex pipiens quinquefasciatus and the effects of Tepa, Metepa and Apholate upon its reproduction. Mosq News. 1970;30(2):149-55.

101. Demirci B, Durmaz E, Alten B. Influence of bloodmeal source on reproductive output of the potential West Nile vector, Culex theileri (Diptera: Culicidae). J Med Entomol. 2014;51(6):1312-6.

102. Richards SL, Anderson SL, Yost SA. Effects of blood meal source on the reproduction of Culex pipiens quinquefasciatus (Diptera: Culicidae). J Vector Ecol. 2012;37(1):1-7.

103. Chang $\mathrm{Y}-\mathrm{YH}$, Judson $\mathrm{CL}$. Amino acid composition of human and guinea pig blood proteins, and ovarian proteins of the yellow fever mosquito Aedes aegypti; and their effects on the mosquito egg production. Compar Biochem Physiol. 1979;62:753-5.

104. Majorek KA, Porebski PJ, Dayal A, Zimmerman MD, Jablonska K, Stewart AJ, et al. Structural and immunologic characterization of bovine, horse, and rabbit serum albumins. Mol Immunol. 2012;52(3-4):174-82.

105. Li S, Cao Y, Geng F. Genome-wide identification and comparative analysis of albumin family in vertebrates. Evol Bioinform Online. 2017:13:1176934317716089.

106. Lea AO, Knierim JA, Dimond JB, DeLong DM. A preliminary note on egg production from milk-fed mosquitoes. Ohio J Sci. 1955;55(1):21.

107. Harris P, Cooke D. Survival and fecundity of mosquitoes fed on insect haemolymph. Nature. 1969:222(5200):1264-5.

108. Bellamy R, Bracken G. Quantitative aspects of ovarian development in mosquitoes. Can Entomol. 1971;103(5):763-73.

109. Stobbart RH. Selection of the yellow fever mosquito Aedes aegypti for cheap and easy maintenance without bloodmeals. Med Vet Entomol. 1992:6(1):87-9.

110. Griffith JS, Turner GD. Culturing Culex quinquefasciatus mosquitoes with a blood substitute diet for the females. Med Vet Entomol. 1996;10(3):265-8.

111. De Wolf FA, Brett GM. Ligand-binding proteins: their potential for application in systems for controlled delivery and uptake of ligands. Pharmacol Rev. 2000;52(2):207-36.

112. Uchida K, Oda T, Matsuoka H, Moribayashi A, Ohmori D, Eshita Y, et al. Induction of oogenesis in mosquitoes (Diptera: Culicidae) by infusion of the hemocoel with amino acids. J Med Entomol. 2001;38(4):572-5.

113. Yen-yun HC, Judson CL. Peptides as stimulators of egg development neurosecretory hormone release in the mosquito Aedes aegypti. Comp Biochem Physiol C Toxicol Pharmacol. 1977:57(2):147-51.

114. Lea AO, Dimond JB, Delong DM. Role of diet in egg development by mosquitoes (Aedes aegypti). Science. 1956;123(3203):890-1.

115. Stipanuk MH. Leucine and protein synthesis: $m T O R$ and beyond. Nutr Rev. 2007:65(3):122-9.

116. Baker KD, Thummel CS. Diabetic larvae and obese flies_emerging studies of metabolism in Drosophila. Cell Metab. 2007:6(4):257-66.

117. Bjedov I, Toivonen JM, Kerr F, Slack C, Jacobson J, Foley A, et al. Mechanisms of life span extension by rapamycin in the fruit fly Drosophila melanogaster. Cell Metab. 2010;11(1):35-46.

118. Kimball SR, Jefferson LS. Amino acids as regulators of gene expression. Nutr Metabol. 2004;1(1):3.

119. Kelen KVD, Beyaert R, Inzé D, Veylder LD. Translational control of eukaryotic gene expression. Crit Rev Biochem Mol Biol. 2009;44(4):143-68.

120. Noriega F, Edgar K, Bechet R, Wells M. Midgut exopeptidase activities in Aedes aegypti are induced by blood feeding. J Insect Physiol. 2002;48(2):205-12.

121. Billingsley PF. Blood digestion in the mosquito, Anopheles stephensi liston (diptera: Culicidae): partial characterization and post-feeding activity of midgut aminopeptidases. Arch Insect Biochem Physiol. 1990;15(3):149-63.

\section{Publisher's Note}

Springer Nature remains neutral with regard to jurisdictional claims in published maps and institutional affiliations. 